\title{
Laboratory and Field Testing of High Performance-Zero Bleed CLSM Mixes for Future Tank Closure Applications
}

by

\author{
C. A. Langton
}

Westinghouse Savannah River Company

Savannah River Site

Aiken, South Carolina 29808

N. Rajendran

\author{
AECENED \\ NOV 161998 \\ OSTI
}

This paper was prepared in connection with work done under the above contract number with the U.S. Department of Energy. By acceptance of this paper, the publisher and/or recipient acknowledges the U.S. Government's.right to retain a nonexclusive, royalty-free license in and to any copyright covering this paper, along with the right to reproduce and to authorize others to reproduce all or part of the copyrighted paper. 


\section{DISCLAIMER}

This report was prepared as an account of work sponsored by an agency of the United States Government. Neither the United States Government nor any agency thereof, nor any of their employees, makes any warranty, express or implied, or assumes any legal liability or responsibility for the accuracy, completeness, or usefulness of any information, apparatus, product, or process disclosed, or represents that its use would not infringe privately owned rights. Reference herein to any specific commercial product, process, or service by trade name, trademark, manufacturer, or otherwise does not necessarily constitute or imply its endorsement, recommendation, or favoring by the United States Government or any agency thereof. The views and opinions of authors expressed herein do not necessarily state or reflect those of the United States Government or any agency thereof.

This report has been reproduced directly from the best available copy.

Available to DOE and DOE contractors from the Office of Scientific and Technical Information, P.O. Box 62, Oak Ridge, TN 37831; prices available from (615) 576-8401.

Available to the public from the National Technical Information Service, U.S. Department of Commerce; 5285 Port Royal Road, Springfield, VA 22161. 


\section{DISCLAIMER}

Portions of this document may be illegible in electronic image products. Images are produced from the best available original document. 
WSRC-TR-98-271

KEY WORDS: Waste Tank Closure

Controlled Low Strength Materials

High-Level Waste Tank Closure

RETENTION: Permanent

LABORATORY - AND FIELD TESTING OF HIGH PERFORMANCE-ZERO BLEED CLSM MUXES FOR FUTURE TANK CLOSURE APPLICATIONS (U)

Authors:

Christine A. Langton,

Westinghouse Savannah River Company

Savannah iver Technology Center,

Aiken, SC 29808

And

N. Rajendran,

Bechtel Savannah River Company

Aiken, SC 29808

Date: March 30, 1998

Westinghouse Savannah River Company

Savannah River Site

Aiken, SC 29808

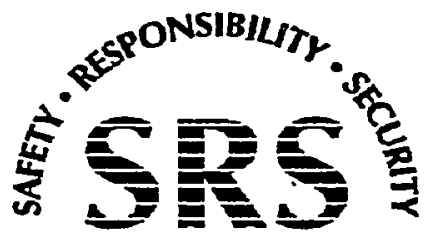

WSRC-RP-98-00244 
WSRC-TR-98-271

KEY WORDS: Waste Tank Closure

Controlled Low Strength Materials

High-Level Waste Tank Closure

RETENTION: Permanent

\section{LABORATORY AND FIELD TESTING OF HIGH PERFORMANCE-ZERO} BLEED CLSM MIXES FOR FUTURE TANK CLOSURE APPEICATIONS-(U)

Authors:

Christine A. Langton, Westinghouse Savannah River Company Savannah iver Technology Center, Aiken, SC 29808

And

N. Rajendran, Bechtel Savannah River Company Aiken, SC 29808

Date: March 30, 1998

Westinghouse Savannah River Company Savannah River Site Aiken, SC 29808

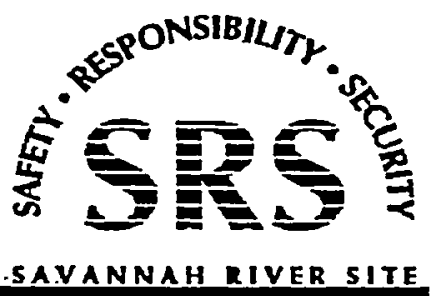


LABORATORY AND FIELD TESTING OF HIGH PERFORMANCE-ZERO BLEED CLSM MIXES FOR FUTURE TANK CLOSURE APPLICATIONS (U)

Author

I

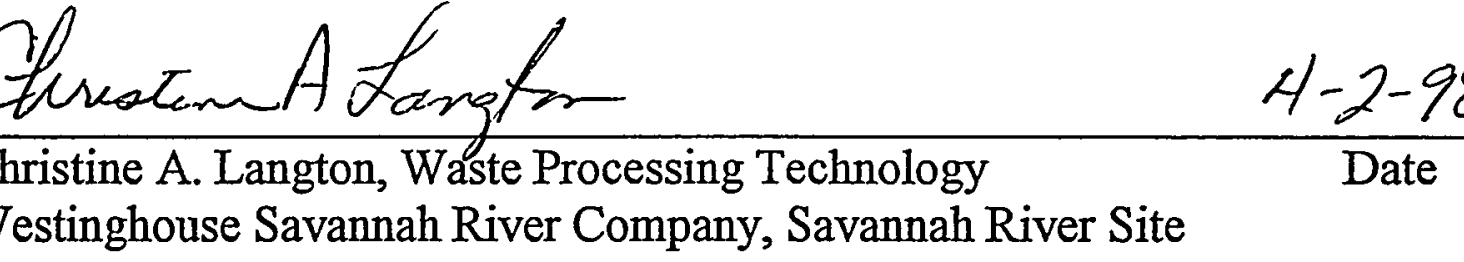

Westinghouse Savannah River Company, Savannah River Site

Aiken, SC 29808

And

N. Rajendran

Bechtel Savannah River Company, Savannah River Site Aiken, SC 29809

Design Check

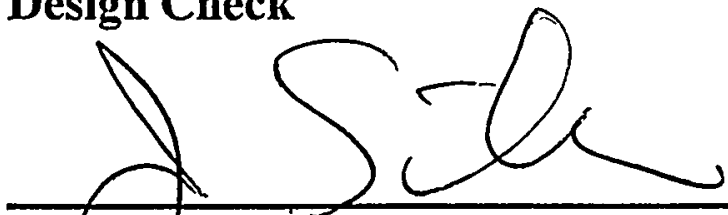

J.Sjler, Waste Processing Technology (per Aanual E7, Procedure 2.40)

\section{Approvals/Review}

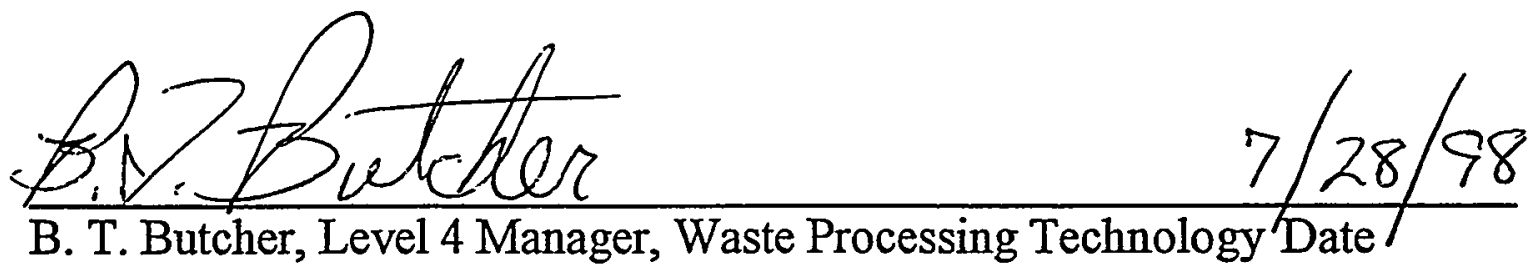




\section{CONTENTS}

SUMMARY 1

BACKGROUND 2

OBJECTIVES - 3

LABORATORY TESTING - 3

Reducing Grout ___ 4

Alternative Additive Systems: Cellular HP-ZB CLSM _ 5

SRS COAL ASH CLSM =-_ 5

Reducing SRS Coal Ash CLSM _-_ 6

LABORATORY RESULTS AND DISCUSSION - 6

Reducing Grout/CLSM - 6

Alternative Additive Systems: Cellular HP-ZB ELSM - 6

SRS COAL ASH CLSM -._- 7

Reducing SRS Coal Ash CLSM _-__ב_ב_ב_ב 7

FIELD TESTING - 8

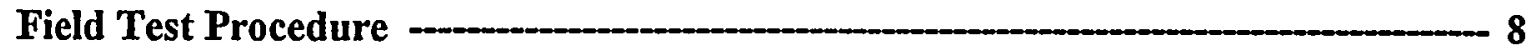

Field Test Acceptance Criteria

FIELD TEST RESULTS 9

DISCUSSION - 10

HP-ZB Reducing Grout/CLSM Versus CTL Reducing Grout _-_ 10

Cellular HP-ZB CLSM Versus HP-ZB CLSM - 10

HP-ZB Area-Area Coal Ash CLSM Versus HP-ZB CLSM 11

HP-ZB Reducing D-Area Coal Ash CLSM - 11

CONCLUSIONS 12

FUTURE WORK 13

REFERENCES -._- 14

ACKNOWLEDGEMENTS 14 


\section{LIST OF TABLES}

1. Reducing CLSM Trial Mix Formulations

Tested at the Raytheon On-Site Laboratory

(CTL Reducing Grout Is Shown for Comparison.)......................... $\quad 15$

2. Cellular (Foamed) CLSM Trial Mix Formulations

Tested at the Raytheon On-Site Laboratory.................................. $\quad 15$

3. A-Area and D-Area Coal Ash Trial Mix Formulations

Tested at the Raytheon On-Site Laboratory................................. 16

4. Reducing CLSM/Grout Trial Mix Test Results............................ 17

5. Cellular (Foamed) ZB CLSM Test Results................................ 17

6. A-Area and D-Area Coal Ash HP-ZB Trial Mix Test Results................ 18

7. Mix Designs Field Tested at the G. L. Throop, Inc.

Auger Batch Plant.............................................................. 19

8. Field Test Results for Reducing Grout/CLSM and

Two Alternative HLW Tank Fill CLSM Mixes, HP-ZB

Cellular CLSM and A-Area Coal Ash HP-ZB CLSM.

9. Comparison of CTL Reducing Grout and HP-ZB Reducing

Grout/CLSM, Mix RG3......................................................

10. Comparison of Tank 17- and 20-F CLSM and Cellular

HP-ZB A-Area Coal Ash CLSM and Cellular HP-ZB CLSM. 


\section{LIST OF PHOTOGRAPHS}

Photograph 1. Reducing HP-ZB CLSM Dry Solids (Sand, Cement, Slag, and Fly Ash) Pre-mixed in a 0.5 Cubic Foot Hobart Mixer

Photograph 2. Consistency of Reducing HP-ZB CLSM (Mix RG3) After the Addition of Water But Before the Addition of the Advaflow and Kelco-Crete. 22

Photograph 3. Consistency and Self-leveling flow of Mix RG3 After Addition of the Advaflow and Kelco-Crete. 23

Photograph 4. Small Foam Generator Used to Prepare the MaxFlow Admixture and a Bucket of the Pre-formed Foam Used in Mixes RGF1 to RGF4 and MF1 and MF2. 24

Photograph 5. Pre-formed Foam was Introduced into the CLSM Mixes After All of the Other Ingredients Were Blended. .25

Photograph 6. Consistency and Flow of a Cellular CLSM Mixture Containing Pre-formed Foam but No High Range Water Reducer.

Photograph 7. Air Content Measurement of a Cellular CLSM Mixture .27

Photograph 8. A-Area Coal Ash Used in CLSM Mixes RGA1, RGA2, RGAF1 to RGAF3.

Photograph 9. Consistency of A-Area Coal Ash Cellular CLSM (Mix RGAF3) After the Addition of Water But Before the Addition of the Pre-Formed Foam.

Photograph 10. Flow Test Sample (Mix RGAF3) Just Prior to the Actual Flow Measurement........................................................30

Photograph 11. Consistency and Self Leveling Flow of Mix RGAF3 After the Addition of Pre-Foamed Foam and the Maxflow RMA High Range Water Reducer.

Photograph 12. G. L. Throop, Inc. Continuous Volumetric Auger Plant Located in F-Area Which was Used for the Pilot-Scale Testing. 32

Photograph 13. Test Form (45 x 3 x 3 Feet) and 5 Inch Diameter Transfer Line Used in the Field Testing. 33 
Photograph 14. Five cubic yards of sand, cement and slag were pre weighed for Mix RG3. This material was subsequently transferred to a concrete mixing truck for batching.

Photograph 15. Dry Solids for Mix RG3 were Weighed at the Troop Plant and Transferred to Super Sacks Which Were Then Emptied into a Concrete Truck for Mixing. After Mixing the CLSM was Discharged to the Grout Pump .35

Photograph 16. Water for Mix RG3 was Measured and Stored in Plastic Containers Which Were Then Emptied into a Eoncrete Truck for Mixing. After Mixing the CLSM was Discharged to the Grout

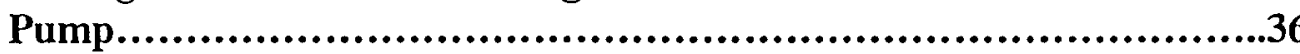

Photograph 17. The MaxFlow Air Admixture was Diluted by W. MacDonald, the Technical Representative from Celcore.

Photograph 18. Foam Generating Equipment Supplied by Celcore, Inc. Which was Used in the Cellular CLSM Field Test.

Photograph 19. A-Area Coal Ash Used in the Field Test of Mix RGF3. This Ash was Delivered from the A-Area Steam Plant in a Dump Truck.

Photograph 20. A-Area Coal Ash was Run Through the Auger Mixer to Crush the Coarse Fraction. No Significant Difference was Observed After Several Passes.

Photograph 21. Appearance of Mix MF2 Immediately After the Auger Mixing as it Enters the Pump Hopper.

Photograph 22. Consistency and Flow of Mix MF2, Cellular CLSM

Collected at the Auger Discharge During the Field Test.

Photograph 23. Consistency and Flow of Mix RGAF3, Cellular A-Area Coal Ash CLSM Collected at the Auger Discharge During the Field Test.

Photograph 24. Flow Characteristics of Reducing CLSM, Mix RG3, in the 45 Foot Long Test Form. .44

Photograph 25. Flow Characteristics of Cellular CLSM, Mix

FM2, in the 45 Foot Long Test Form After Pumping. 
WSRC-TR-98-00271

March 30, 1998

Photograph 26. Flow Characteristics of Celluar A-Area Coal

Ash CLSM, RGAF3, in the 45 Foot Long Test Form...................... 46 
WSRC-TR-98-00271

March 30, 1998

Page 1 of 46

\section{WESTINGHOUSE SAVANNAH RIVER COMPANY SAVANNAH RIVER TECHNOLOGY CENTER}

\section{LABORATORY AND FIELD TESTING OF HIGH PERFORMANCE-ZERO BLEED CLSM MIXES FOR FUTURE TANK CLOSURE APPLICATIONS (U)}

Christine A. Langton

Westinghouse Savannah River Company

Savannah River Technology Center, Aiken, SC 29808

N. Rajendran

Bechtel Savannah River Company

Aiken, SC 29808

\section{SUMMARY}

Three high performance, zero bleed controlled low-strength material mixes-(HP-ZB CLSM) were designed and tested in the laboratory and under field conditions. These mixes are pumpabe, easy to batch, and meet the placement requirements for high-level waste tank closures. The mix designs and engineering properties of the trial mixes are presented in this report. In addition, a preliminary materials cost comparison suggests that a significant savings may be realized by utilizing the one or more of these alternative mix designs in future tank closures

Five All-In-One reducing CLSM mixes (covering a range of compressive strengths), a cellular CLSM (alternative HP-ZB admixture system), and a CLSM containing A-Area coal ash were formulated in the laboratory test program conducted at the Raytheon on-site concrete testing laboratory.

The All-In-One reducing CLSM mixes were designed as an alternative for the three layer grout concept used in Tanks 17 and 20 The All-In-One CLSM is a single material which meets both the chemistry requirements for encapsulating incidental waste in addition to the placement requirements for filling the bulk of the high-level waste tank These mixes were based on substituting Grade 100 slag for some of the fly ash in the HP-ZB CLSM formulation used to filling Tanks 17 and 20-F. One of these mixes with a compressive strength in the mid range was selected for field testing.

The cellular CLSM mix was developed as the result of testing alternative HP-ZB admixture systems. The best alternative system identified was a combination of a pre-formed foam and a dispersant. This admixture system resulted in zero-bleed, self-leveling CLSM with a cellular microstructure.

An HP-ZB CLSM mix containing A-Area coal ash was also developed as an alternative for the HP-ZB CLSM used as the bulk fill material for tank closures. This mix is also cellular and contains the same admixture system described above 
Based on the laboratory test results, one mix from each category was selected for field testing at the G. L. Throop, Inc. continuous auger batch plant located in F-Area. Field testing took place December 16 to 19, 1997 and consisted of mixing and pumping up to five cubic yards of each mix about 250 feet (76 meters) through a 5 inch $(127 \mathrm{~cm})$ line. The slick line discharged into a plywood form $3 \times 3 \times 45$ feet long ( $09 \times 09 \times 13.7$ meters) Samples were collected for flow testing, unit weight, air content, bleed water, set time, and compressive strength at the auger mixer discharge and also at the end of the 250 foot (76 meter) transfer line. The flow in the plywood form was observed and documented. The flow distance in the form was one half of the diameter of the HLW tanks and was used to approximate the travel distance required for a central discharge.

Future work in FY 98 and FY 99 includes designing and laboratory testing of an All-In-One, AArea coal ash mix and a modified three component All-In-One CLSM for high-level waste tank applications (cement, slag and sand). At the completion of this program, new fill materials will be available as lower cost options (compared to tanks 17 and 20-F) for future high-level waste tank closures.

This work was funded by the SRTC Strategic Research and Development (SR\&D) Program. Also, development of the A-Area coal ash CLSM was partially funded by the DOE Tank. Focus Area.

\section{BACKGROUND}

Two high-level waste (HLW) tanks were closed at the SRS in 1997. Approximately twelve thousand cubic yards (9000 cubic meters) of the first generation HP-ZB CLSM and about two thousand cubic yards (1500 cubic meters) of the first generation $2000 \mathrm{psi}(13.8 \mathrm{MPa}$ ) intruder barrier grout were used in this effort The HP-ZB CLSM and the HP-ZB 2000 psi grout used in the 1997 $\mathrm{HLW}$ tank closures were designed by SRTC and BSRI. In addition, 5030 and 1330 cubic yards of reducing grout was used to encapsulate incidental waste in Tanks 17- and 20-F, respectively. The reducing grout was designed for SRS by the Construction Technology Laboratory, Skokie, IL.

High performance-zero bleed CLSM is defined as flowable fill, which is self-leveling, self compacting, cohesive, and has no bleed water (no phase separation). In the HLW tank closure applications, these materials must also flow up to 45 feet (13 7 meters). In addition, the high performance mixes have low heats of hydration and a range of compressive strengths which allow the basic material to be tailored to meet specific design requirements.

A special combination of admixtures was identified to achieve the HP-ZB features of the mixes used in the Tank 17-F and 20-F closures. This system was a blend of an ASTM Class F high range water reducer (HRWR) (Advaflow) and a thickener (Kelco-Crete). This admixture system is expensive and adds about $\$ 18$ per cubic yard to the cost for common CLSM and 2000 psi grout. Research reported here was initiated to identify opportunities for performance and cost improvements in the $\mathrm{HLW}$ tank closure materials 
WSRC-TR-98-00271

March 30, 1998

Page 3 of 46

The work summarized in this document was funded as three separate tasks in the SRTC SR\&D proposal, Improved Fill Materials for High-Level Waste Tank Closures. These tasks are:

Task I. Identify alternative admixture systems for HP-ZB CLSM. Lower cost admixtures will reduce the materials cost for future tank closures.

Task II. Develop reducing grout/CLSM Reducing grout/CLSM mix designs will provide options for materials to both encapsulate incidental waste-and to fill the-HLW tanks.

Task III. Develop SRS coal ash CLSM for tank closures. Use of by-product materials such as the SRS coal ashes is a waste minimization effort.

Task IV. Develop HP-ZB CLSM mixes which contains SRS soil. This task will be conducted in FY 99.

Task V. Develop a pumpable, zero-bleed, self-leveling mix which contains slag and SRS coal ash. (This task was added to the scope to this project at the request of $\mathrm{HLW}$ engineering. An additional $\$ 50 \mathrm{~K}$ was provided by $\mathrm{HLW}$ via a WAD to support this effort.)

\section{OBJECTIVES}

The work performed in this project is intended to support the SRS and DOE complex effort to close high-level waste tanks. Alternative materials were investigated to stabilize the incidental waste remaining in the tanks (Reducing Grout), to prevent future subsidence (HP-ZB CLSM), and to provide intruder barriers (2000psi Grout). The specific objectives of this program are listed below:

1) Identify lower cost additives which will result in pumpable, zero bleed, self-leveling fill materials.

2) Develop a single fill material (All-In-One reducing CLSM) instead of three different materials for closing the tanks.

3) Develop a pumpable, zero-bleed, self-leveling mix which utilizes SRS coal ash instead of sand and Class F fly ash

One mix which met the performance criteria for each of the three objectives listed above was selected for field testing to confirm properties measured in the laboratory.

\section{LABORATORY TESTING}

Laboratory screening tests were conducted on 18 initial systems These mixes included lignosulfonated based and melamine based HRWR admixtures which either did not mix well with the Kelco-crete or which did not result in zero bleed mixes Based on the feasibility data, the most promising system was selected for each of the zero bleed products (reducing grout/CLSM, alternative CLSM, and coal ash CLSM). Trial mixes were then designed and tested for each product. The tests, test protocols, and acceptance criteria are listed below. 


\begin{tabular}{|c|c|c|}
\hline PROPERTY & $\begin{array}{c}\text { ASTM } \\
\text { REFERENCE }\end{array}$ & $\begin{array}{l}\text { HLW TANK FILL } \\
\text { ACCEPTANCE } \\
\text { CRITERIA }\end{array}$ \\
\hline Flow & D- 6103 & $\begin{array}{c}10 \text { inches } \\
\text { (minimum) }\end{array}$ \\
\hline Bleed Water. & C-232 & $\begin{array}{c}\text { Zero vol. \% after } \\
24 \mathrm{hr} \\
\end{array}$ \\
\hline Air Content & $\mathrm{C}-231$ & N/A \\
\hline Unit Weight & C-138 & $\begin{array}{c}80 \mathrm{lbs} / \mathrm{ft}^{3} \\
(\text { minimum })\end{array}$ \\
\hline Set Time & $\mathrm{C}-403$ & 30 hours (max.) \\
\hline Compressive Strength & $\mathrm{C}-39$ & \\
\hline $\begin{array}{l}\text { Reducing grout/CLSM } 7 \\
\text { days }\end{array}$ & & 50 psi (min.) \\
\hline days 28 & & 500 psi (min.) \\
\hline days 56 & & 500 psi (min.) \\
\hline $\begin{array}{l}\text { Cellular CLSM and } \\
\text { HP-ZB Coal Ash CLSM }\end{array}$ & & \\
\hline $\begin{array}{ll}\text { days } & 7 \\
\end{array}$ & & $20 \mathrm{psi}$ (min.) \\
\hline days 28 & & $50 \mathrm{psi}(\mathrm{min})$. \\
\hline $\begin{array}{ll}\text { days } & 56 \\
\end{array}$ & & $120 \mathrm{psi}$ (min.) \\
\hline $\begin{array}{ll}2000 \text { psi grout } & 28 \\
\text { days }\end{array}$ & & 2000 psi (min.) \\
\hline
\end{tabular}

\section{Reducing Grout/CLSM}

The reducing grout/CLSM mixes were developed by modifying the HP-ZB CLSM formulation used as stabilizing fill in Tanks 17- and 20-F. The amount of Grade 100 blast furnace slag was varied from 210 (same as the current reducing grout) to 275 pounds per cubic yard. The slag was substituted for an equivalent portion of the fly ash in the HP-ZB CLSM mix In addition, the cement content was varied from 50 to $150 \mathrm{lbs} / \mathrm{cyd}$ in order to produce mixes with a range of compressive strengths. Type I Portland cement, Class F fly ash and ASTM C-33 concrete sand were used in all of these mixes. The same admixture system (Advaflow and Kelco-Crete) and dosage used in the HP-ZB CLSM was used in all of the reducing grout/CLSM mixes.

Mix designs for the CTL reducing grout ${ }^{3}$, the HP-ZB CLSM and the six reducing grout/CLSM formulations tested in this study are shown in Table 1. Photographs 1 to 3 illustrate preparation of the reducing grout/CLSM in the Raytheon Laboratory. The batch size was 0.5 cubic feet. Mixing was conducted in a Hobart planetary mixer. Photograph 1 illustrates the mixture of dry ingredients. Photograph 2 illustrates the stiff consistency of these mixes before the high performance admixture 
system is introduced. Photograph 3 illustrates the self leveling characteristic of Mix RG3 after the addition of the admixture system (Advaflow plus Kelco-Crete). This mix was self-leveling and had a flow of 11.5 inches per the ASTM D 6103 Flow Consistency Test

\section{Alternative Admixture Systems: Cellular HP-ZB CLSM}

Alternative admixtures and admixture systems were evaluated for HP-ZB CLSM The strategy was to first substitute the admixture system in the original HP-ZB CLSM formulation. Several alternative high-range water reducing (HRWR) admixtures were evaluated in the HP-ZB systems. All of these were eliminated from further testing for one of the following reasons. they were not cost effective; there was a problem incorporating them into the actual mix, the resulting mixes were not self leveling; and/or bleed water was not completely eliminated. These systems included melamine-based HRWR admixtures plus Kelco-Crete, lignosulfonate-based HRWR plus KelcoCrete, and surfactants for cellular, low density cement products. Of all the alternative systems tested, the liquid and powdered high-air admixtures demonstrated potential in controlling the bleed water and enhancing flow. ${ }^{1}$ However, these admixtures are difficult to add in a volumetric continuous batching facility, such as, the one used for closing Tanks 17- and 20-F.

Since modified HP-ZB CLSM mixes with high air contents showed potential for use in the tank closure program, pre-formed foam was tested as an alternative method for adding air to the CLSM mixes. (The pre-formed foam can be pumped into the auger mixer in a continuous batch plant and mixed along with the other ingredients ) MAXFLOW AIR, (pre-formed foam) was identified and tested in CLSM mixes by the technical staff at Celcore, Inc, NC This admixture is a surfactant and is sold as a liquid. The MAXFLOW AIR is mixed with water and processed into a stiff foam. The foam can be either injected into the mixer through a calibrated nozzel or manually added to a batch mixer. The foam is prepared to a specified density and added to the CLSM to achieve a specified product density.

The small foam generator used to prepare the test mixes at the Raytheon laboratory is shown in Photograph 4. In the laboratory, the pre-formed foam was introduced into the CLSM mix after all the other ingredients were blended as shown in Photograph 5 Photographs 6 and 7 illustrate flow and air content testing of cellular CLSM made in the laboratory. The ingredients and the proportions used in the cellular CLSM mixes tested are shown in Table 2. Three of these mixes contained a fluidifier in addition to the pre-formed foam. Mix RGF4 contained welan gum as a thickener.

\section{SRS Coal Ash CLSM}

The HP-ZB SRS coal ash mixes were developed by modifying previously developed A-Area and DArea ash mix designs ${ }^{2}$ Photograph 8 illustrates the A-Area coal ash used in this study. This material came directly from the A-Area power house. It is a mixture of bottom ash, clinker, and fly ash. This material had a moisture content of about $20 \mathrm{wt}$. \% at the time of testing because water was sprayed on the ash to control dust during transportation from A-Area to N-Area.

The original A-Area coal ash mix had a considerable amount of bleed water since it is intended to be used as a common backfill used in place of compacted soil. ${ }^{2}$ Consequently, several approaches were tested to reduce the bleed water in the SRS ash mixes. These included using:

1) HP-ZB admixture system (Advaflow plus Kelco-Crete),

2) Foaming agent (MAXFLOW AIR), 
3) Foaming agent (MAXFLOW AIR) plus HRWR fluidifier (MAXFLOW RMA).

Mix designs tested in the laboratory are shown in Table 3. It should be noted that a large portion of the coarse material in the A-Area ash can be broken into smaller pieces by the small laboratory Hobart mixer. Photograph 9 illustrates the consistency of a typical A-Area coal ash mix before addition of the pre-formed foam Photograph 10 illustrates the appearance of an A-Area coal ash CLSM just prior the actual flow test measurement. Photograph 11 illustrates that the pre-formed foam A-Area coal ash mix, RGAF3, is flowable, cohesive and has no segregation.

\section{Reducing SRS Coal Ash CLSM}

Three mixes were made to evaluate the effect of substituting.slag.for some of the A- and D-Area coal ashes. These mix designs are also shown in Table 3 and results are included in the discussion. These mixes represent the first attempt to develop an All-In-One Reducing Coal Ash CLSM for closure of the high-level waste tanks

\section{LABORATORY RESULTS AND DISCUSSION}

\section{Reducing Grout/CLSM}

Results for the reducing grout/CLSM trial mixes are shown in Table 4 All of six mixes tested met the flow, bleed, set time, and strength requirements. The mixes differed in compressive strengths due to variation in the cement contents. All mixes exceeded the 500 psi reducing grout compressive strength requirement at 28 days (The reducing grout is used for encapsulation/stabilization of the incidental HLW which can not be removed from the tanks Therefore, the strength requirement is higher than the CLSM fill material )

In comparison to the CTL reducing grout which contained Type V Portland cement, all of the reducing grout/CLSM mixes developed in this study contained locally available Type I Portland cement. The reducing grout/CLSM also contained about one tenth the amount of cement, but the same amount of slag as the CTL grout Silica fume was not used in the new reducing grout/CLSM mixes. The HP-ZB admixture system (Advaflow-Kelco-Crete) was used in these mixes to control segregation and bleed. This admixture system also provided the desired flow and self leveling properties.

Based on the relatively high 56 day compressive strength results, it is apparent that the slag is reactive and makes a significant contribution to the matrix properties in these mixes. In addition, these data indicate that zero bleed reducing grout/CLSM mixes can be designed to achieve a wide range of compressive strengths by adjusting the cement and slag contents without major changes in the other ingredients

\section{Alternative Admixture Systems: Cellular HP-ZB CLSM}

The cellular CLSM mixes are based on the original HP-ZB CLSM The cement and fly ash contents are almost the same as the HP-ZB CLSM However, pre-formed foam made from the MAXFLOW AIR admixture was substituted for a large amount of the sand.

All of the mixes were light-weight ( 80 to $90 \mathrm{lbs} / \mathrm{cft}$ ) compared to the HP-ZB CLSM (125 to 130 $\mathrm{lbs} / \mathrm{cft}$ ) used in the Tank 17- and 20-F closures. This is because the cellular HP-ZB mixes had air 
WSRC-TR-98-00271

March 30, 1998

Page 7 of 46

contents between 18 to 28 volume percent and up to $45 \mathrm{wt} \%$ less sand. The compressive strengths of these cellular HP-ZB CLSM mixes were also lower than those measured for the HP-ZB CLSM used in the tank closures. One mix, MF1, had a 28 day compressive strength below $50 \mathrm{psi}$, the acceptance value for HLW fill CLSM.

All of these mixes had acceptable flows (greater than 10.5 inches) and were self leveling. However, the mixes containing only the pre-formed foam had bleed water The mixes containing the preformed foam plus a fluidifier, MAXFLOW RMA, did not have bleed water. Consequently this combination of admixtures is recommended as an alternate system. Test results for the cellular CLSM mixes containing the alternative admixtures are shown in Table 5.

Unique advantages of the pre-formed foam cellular CLSM mixes include:

1) less load transferred to the HLW tank foundation and tank walls.

2) less material used per cubic yard of fill results in lower materials cost per cubic yard.

3) less expensive admixture system compared to the HP-ZB CLSM.

4) admixture addition is compatible with continuous volumetric batching

\section{SRS Coal Ash CLSM}

Zero Bleed CLSM mixes were successfully made using both A- and D-Area coal ashes, mixes RGAF3 and RGD1 and RGD2; respectively Mix RGAF3 contained the MAXFLOW AIR and RMA admixture system and appeared to be the least sensitive to minor variations in proportioning. The A-Area coal ash mix was cohesive even though the particle size is very irregular. This mix was selected for the field testing.

Slag was added to three of the coal ash mixes, RGA1, RGD1 and RGD2. The slag was added to increase the proportion of fine particles to improve flow and minimize segregation. The mixes were also the first attempt to formulate reducing coal ash CLSM. Both of the D-Area ash mixes containing slag met the acceptance criteria for $\mathrm{HLW}$ tank fill. These mixes contained the original HP-ZB admixture system (Advaflow-Kelco-crete). The reducing A-Area coal ash mix contained only the Advaflow. Since the Kelco-crete (welan gum) was not included in this mix, bleed water was generated. The other A-Area ash mixes, RGAF1 and RGAF2 contained pre-formed foam but no fluidifier and also generated bleed water

The coal ashes from the A- and D-Areas differed considerably in particle size. ${ }^{2}$ Consequently, different types of admixture systems were required to suspend the particles and prevent settling in the CLSM mix designs The A-Area ash tested in this study contained pieces of clinker up to about 05 inches in size. The pre-formed foam was most suited for supporting these large pieces of material. The D-Area ash tested in this study was primarily fly ash (less than 200 mesh) material. Consequently, the original HP-ZB admixture system developed for tank closure CLSM, the Kelcocrete (welan gum) in particular, was capable of supporting the particles and preventing phase separation.

Results for all of the SRS coal ash mixes tested in this study are given in Table 6. 


\section{FIELD TESTING}

\section{Field Test Procedure}

Three trial mixes which met all of the acceptance criteria were selected for field testing. These mixes were the reducing grout/CLSM (RG3), the cellular HP-ZB CLSM (MF2) and the cellular AArea coal ash CLSM (RGAF3). The mix designs batched in the field test are also shown in Table 7. The field test was conducted December 16 to 19,1997 at the G. L. Throop, Inc. continuous volumetric batch plant located in F-Area. The batch plant is shown in Photograph 12.

The field test plan consisted of batching up to 5 cubic yard of each mix and pumping the batches through a 5 inch $(12.7 \mathrm{~cm})$ line about 250 feet $(76$ meters) in to a ply wood form. The form was 45 feet long, 3 feet wide and 3 feet high ( $09 \times 09 \times 13.7$ meters) and is shown in Photograph 13. The form was intended to simulate the flow distance required if the grout or CLSM is placed into a HLW tank (85 feet in diameter) through the center riser

The reducing grout/CLSM was pumped with one of the piston grout pumps used by BSRI construction personnel in the tank closure program. The two cellular CLSM mixes were pumped with a positive flow (squeeze) pump supplied by Celcore, Inc

This field test was conducted after Tank 17-F was closed Due to the limited availability of the grout batching equipment at the end of the contract, there was only enough time to batch two mixes in the auger equipment Consequently, the two cellular CLSM mixes were selected for continuous auger batching in the G L. Throop Inc. equipment because both mixes contained ingredients which were novel and beyond the conventional experience of the SRS, Throop and Celcore personnel

Since the reducing grout/CLSM mix was a slight modification of the 12,000 cubic yards of HP-ZB CLSM already pumped, this mix was selected for alternative batching in a ready mix truck. The ingredients were pre weighed using the Throop equipment, stored in super sacks and dumped into the ready mix truck using a forklift See Photographs 14, 15 and 16. Mixing was conducted per the ASTM standard practice for this type of batching (ASTM C-94).

The MAXFLOW AIR admixture was mixed with water and prepared for the foam generator by W. MacDonald from Celcore Inc as shown in Photograph 17. The foam generating equipment supplied by Celcore is shown in Photograph 18. The pre-formed foam was pumped in to the front end of auger barrel. The Fluidifier, MAXFLOW RMA was also pumped into the auger barrel through the same port used for the Advaflow-Kelco-crete used in the original HP-ZB mixes.

The A-Area coal ash used in mix, RGAF3, was delivered from the A-Area steam plant in a dump truck (Photograph 19) This material was run through the auger mixer in the Throop batching plant two times to crush the coarse fraction (Photograph 20). Very little crushing was accomplished. 
WSRC-TR-98-00271

March 30, 1998

Page 9 of 46

\section{Field Test Acceptance Criteria}

The acceptance criteria for the CLSM mixes prepared and placed under field conditions were the same as those listed for the laboratory samples. The following criteria were especially relevant to the production and placement in the field

1) easy to mix and easy incorporation of admixtures

2) pumpable

3) flow test result of at least 10.5 inches for samples collected at the auger and slick line discharge points per the ASTM D-6103 flow test

4) flow 45 feet in the form

5) zero bleed water in samples collected for observation and for material placed in the form

6) meet minimum strength at 28 days for samples collected at the discharge.

7) set within 30 hours for samples collected at the auger discharge and for material placed in the form

8) cohesive, no segregation for samples collected at the auger discharge and for material placed in the form

\section{FIELD TEST RESULTS}

The three self-leveling, zero bleed CLSM mixes batched in the continuous auger mixer in F-Area performed as expected The mixes were uniform in appearance upon being discharged from the auger barrel, self-leveling in the form, had no bleed water, and set within 24 hours. Slurry properties were measured in the field and samples were collected and transported to the Raytheon Laboratory for curing and subsequent evaluation. ASTM procedures listed for the laboratory evaluation were followed Results are presented in Table 8.

Samples were also collected for fresh unit weight, air content, temperature, bleed water, set time and compressive strength Photograph 21 illustrates the appearance and flow of the cellular HPZB mix, MF2, as it was discharged from the auger and flowed into the pump hopper. Photograph 22 illustrates the appearance and self-leveling nature of this same mix after the flow test. Photograph 23 illustrates the appearance of mix RGAF3, the cellular A-Area ash mix after the flow test. The flows of both of these mixes per the ASTM D-6103 procedure were measured at more than 13 inches. Photographs 24 through 26 illustrate the flow characteristics of mixes RG3, MF2 and RGAF3, respectively, in the 45 foot long test form after pumping. Excellent correlation was obtained between the flow test results and actual flow in the test form In addition, these mixes did not segregation or bleed in the form or in any of the cured samples. These samples set within 24 hours.

The reducing grout mix, RG3, resembled the CLSM used in the Tank 17 and 20 closures. A small amount of bleed water was observed on samples of this mix cured in the laboratory after 12 hours of curing. However this water was reabsorbed by the sample within 48 hours. The observed bleed water in this mix was due to a small amount of extra water in the mix. The source of this water was wash water, which was inadvertently left in the truck mounted mixing drum used to batch this particular mix (In order to complete the field testing within the scheduled time, the reducing grout mix was mixed in a concrete truck rather than in the auger mixer.) 


\section{DISCUSSION}

\section{HP-ZB Reducing Grout/CLSM Versus CTL Reducing Grout}

The HP-ZP reducing grout/CLSM mixes meet the acceptance criteria for encapsulation of incidental $\mathrm{HLW}$ in the tank closure program These mixes contain the same amount of slag as the CTL reducing grout and can incorporate sodium thiosulfate as an additional reducing agent. Consequently the $\mathrm{E}_{\mathrm{h}}$ (controlled by slag and sodium thiosulfate) of these materials is identical. The alkalinity $(\mathrm{pH})$ of the two types of material is also similar. However, the total alkaline capacity of the reducing HP-ZB grout/CLSM is probably less than that of the CTL reducing grout since less cement is used in the HP-ZB reducing CLSM. (This is difficult to estimate since silica fume is used in the CTL material. Silica fume is very reactive and in the presence of calcium hydroxide reacts to form hydrated phases which results in lowering the overall alkalinity of the system.)

The difference in cement contents of the reducing HP-ZB grout/CLSM mixes and the CTL reducing grout is also the primary reason for differences in the physical properties observed-for these two types of stabilization/encapsulation materials The compressive strengths of the reducing HP-ZB grout/CLSM mixes were considerably lower than that of the CTL reducing grout The heat generated by the chemical reactions responsible for the cement hydration was also much less for the reducing HP-ZB CLSM mixes compared to the CTL reducing grout Consequently the temperatures observed in the pours were different, more than $300^{\circ} \mathrm{F}$ for the CTL reducing grout compared to about $120^{\circ} \mathrm{F}$ for the reducing HP-ZB CLSM mixes

A lower temperature rise benefits the construction schedule by not limiting the placement quantity because of curing temperature concerns. Because of the lower temperature of the reducing CLSM, thermal and shrinkage cracking will be less for the reducing CLSM compared to the reducing grout.

A comparison of an All-In-One Mix, RG3, batched and pumped in the field test, and the CTL reducing grout is shown in Table 9.

\section{Cellular HP-ZB CLSM Versus HP-ZB CLSM}

Pre-formed foam plus a compatible fluidifying admixture constitute an acceptable, lower cost admixture system for high-performance, zero-bleed CLSM The Cellular HP-ZB CLSM mix field tested in this study met the acceptance criteria for the $\mathrm{HLW}$ tank fill material A comparison of the Tank 17- and 20-F CLSM and the cellular HP-ZB CLSM mix evaluated in the field test (MF2) is shown in Table 10

The compressive strength of the cellular HP-ZB CLSM is about $50 \%$ of the compressive strength of the tank fill CLSM for both 28 and 90 days of curing The strength of the cellular mix met the HLW tank fill requirement However, higher or lower compressive strengths can be obtained by adjusting the cement content (over the range of at least 75 to $300 \mathrm{lbs} / \mathrm{cyd}$ ) to achieve the desired value. The flow and self-leveling properties of mix MF2 were even better than the original HP-ZB mix used to fill Tanks 17- and 20-F. No bleed water was observed for this mix. The addition of the pre-formed foam results in a lighter weight product with a cellular structure. The mix batched in the field had a higher unit weight than the samples prepared in the laboratory (98 versus 80 lbs/cyd, respectively) The higher density obtained in the field test was intentional and was the result of optimizing the appearance, consistency and flow of the field product. 
Advantages of a lighter weight fill include less loading on the HLW tank walls and foundation and less sand required to produce a given volume. In addition, the closed cell structure of the light weight material typically results in lower permeabilities than measured for an identical mix without the closed cell structure.

\section{HP-ZB A-Area Coal Ash CLSM Versus HP-ZB CLSM}

A-Area coal ash was substituted for all of the sand in the mix design for this HP-ZB CLSM. This was the first demonstration of the successful batching of a no sand HP-ZB CLSM at the SRS. A comparison of the cellular HP-ZB A-Area coal ash CLSM and the other HP-ZB CLSM mixes tested is presented in Table 10.

Since the A-Area ash sample used in the laboratory and field test had a particle size distribution which was characterized by a large amount of coarse material, Class $F$ fly ash and extra cement were added to the mix design to enhance flow and cohesion The amount of water was also increased relative to the other mixes tested because the coal ash contained some porous aggregates and clinker which adsorbed water, thereby increasing the water demand for a fluid mix.

The compressive strength of the HP-ZB A-Area ash CLSM was considerably lower than the strength of the CLSM use to fill Tanks 17- and 20-F. However, the mix batched and placed in the field test still met the minimum strength requirements The strength of the cellular HP-ZB ash mix was also significantly than the cellular HP-ZB CLSM field tested ( 55 versus 135 psi at 28 days). Since the A-Area coal ash has a lower compressive than ASTM C-33 concrete sand, the ashcontaining CLSM mixes do not have the same compressive strength potential as the conventional sand-containing mixes. In addition, the extra water required to achieve a self leveling material contributed to the lower strength Based on the results obtained in both the laboratory and field testing, the compressive strength of the A-Area ash mixes can be increased, if desired, by substituting slag for the fly ash, or by increasing the amount of cement, and/or by decreasing the amount of mixing water.

\section{HP-ZB Reducing D-Area Coal Ash CLSM}

Two self-leveling, zero bleed mixes containing D-Area coal ash and slag were formulated in the laboratory. These mixes are examples of All-In-One SRS coal ash CLSM and are suitable for HLW tank fill The original HP-ZB admixture system was used in the two reducing D-Area ash mixes prepared in the Raytheon laboratory A combination of D-Area ash and slag was substituted for Class F fly ash in one of these mixes, RGD1 In the other mix, RGD2, D-Area ash was substituted for all of the Class F fly ash and all of the ASTM C-33 concrete sand.

Based on the compressive strength values at 56 days (740 and 970 psi for mixes RGD1 and RGD2, respectively), both of these reducing D-Area ash mixes also have potential for replacing the CTL reducing grout used for encapsulation of the incidental waste. Based on test results, about 1700 pounds of D-Area ash can be used in each cubic yard of All-In-One coal ash CLSM.

The average particle size of the D-Area ash is finer than that of the A-Area ash In addition, the overall particle size distribution of the D-Area ash is similar to that of the cement and fly ash used in the HP-ZB CLSM. ${ }^{2}$ Consequently, the Advaflow-Kelco-crete admixture system was effective in both types of mix designs The pre-formed foam-fluidifier system tested as an alternative to the original HP-ZB admixtures should also be suitable for D-Area ash mixes. 


\section{CONCLUSIONS}

Laboratory and field testing of new High-Level Waste tank fill materials was conducted to identify new, alternative fill materials for future HLW tank closures at SRS The following new materials were developed and successfully field tested

- A reducing grout/CLSM based on modification of the formulation of the CLSM used to fill Tanks 17-and 20F This mix design can be used as an All-In-One grout/CLSM for both incidental waste encapsulation/stabilization and for filling the bulk of the tank.

- An alternative HP-ZB admixture system (MAXFLOW AIR plus MAXFLOW RMA) was identified for CLSM suitable for HLW tank fill This new admixture system contains a foaming agent which is used to generate a pre-formed foam and a compatible fluidifying (HRWR) reagent. This alternate system cost less than the-Advaflow-Kelco-crete system used in the tank 17 - and $20-\mathrm{F}$ closure

A cost savings of about $\$ 8$ per cubic yard was estimated for the cellular HP-ZB CLSM versus the tank 17- and 20-F HP-ZB CLSM

- HP-ZB A-Area coal ash CLSM was successfully formulated and field tested. The pre-formed foam admixture system is best suited for HP-ZB CLSM mixes containing A-Area ash. A-Area ash was used in place of all of the sand in the CLSM mix design. About 1500 pounds of A-Area ash can be used per cubic yard of HP-ZB CLSM. This ash is not suited as a complete replacement for all of the fly ash in the CLSM mix Consequently, fines must be added as Class F fly ash, and/or cement

Formulation work to date has resulted in A-Area ash CLSM mixes which meet the requirements for the HLW tank fill

- HP-ZB D-Area coal ash CLSM was successfully formulated and evaluated in the laboratory. The result was a reducing All-In-One CLSM.

The reducing D-Area ash mixes tested in the laboratory have physical and chemical properties which make them suitable for replacing both the CTL reducing grout and the tank fill CLSM. The original Advaflow-Kelco-crete admixture system was used

The D-Area ash can replace all of the fly ash or all of the sand plus the fly ash in HP-ZB CLSM formulations About 1700 pounds of D-Area ash can be used per cubic yard of HP-ZB CLSM if both the sand and Class F fly ash are replaced. Slag was added to these mixes in the same amount as used in the CTL reducing grout $(210 \mathrm{lbs} / \mathrm{cyd})$

- CLSM containing D-Area ash was not field tested because the sand hopper in the G. L. Throop plant may have required modification to handle this ash. The D-Area ash tends to form a paste due to the fine particle size when it is wet. Consequently gravity flow out of the hopper was assumed to be a problem If the D-Area ash is used, a suitable solids handling system (vibrating chains on the hopper, auger feeding, etc ) must be provided.

- Use of SRS coal ash in tank fill CLSM/grout will require additional quality control monitoring for the ash Moisture content and gross particle size distribution must be monitored. Screening the ash and covered storage should be considered 


\section{FUTURE WORK}

Future work includes

- Reduction in the number of solid components from 4 to 3 in the All-In-One Reducing grout/CLSM mix design is desirable The mixes developed in this study contained cement, slag, fly ash, and sand Eliminating one of these ingredients will simplify calibration, materials storage, and feeding in a continuous auger batch plant. (The number of solid ingredients does not impact the operation and efficiency of a central mixing plant as much as it does a mobile auger plant )

The fly ash will be replaced with slag in the next generation of-All-In-One grout/CLSM mix designs. This will maintain the same proportion of fines to sand and will be slightly less expensive than using cement

- Reducing A-Area coal ash HP-ZB CLSM mixes will be designed and tested in the laboratory. These mixes will be another option for the reducing CLSM It is doubtful that the strength required for the reducing encapsulating grout can be obtained with the reducing A-Area coal ash mixes.

- Cellular D-Area coal ash CLSM with and with out slag will be designed and tested in the laboratory.

- Additional work on HP-ZB admixtures will be conducted

- Shrinkage properties of the cellular HP-ZB CLSM and grout will be evaluated. The high air contents of these mixes make them sensitive to thermal expansion and contraction prior to setting If the temperature or the placement environment is warmer than in the mixing environment, the air in the CLSM will expand in the warmer placement environment. Similarly, if the placement environment is cooler than the mixing environment, the air in the cellular structure will contract and the CLSM will shrink This only occurs before the CLSM sets. However, the effects on bleed water generation are unknown

- HP-ZB soil CLSM will be developed as an alternative for tank fill and also as a potential landfill cap and stabilization material 


\section{REFERENCES}

1. WSRC-RP-97-271, C. Langton and N. Rajendran, CLSM Bleed Water Reduction Test Results (U), April 21, 1997.

2. WSRC-RP-95-1026, Rev 0, C. Langton and N. Rajendran, Utilization of SRS Pond Ash in Controlled Low Strength Material (U), December 1995.

3. WSRC-TR-97-0102, T. B. Caldwell, Tank Closure Reducing Grout (U), April 15, 1997.

\section{ACKNOWLEDGEMENTS}

B. L. Mhyer, M. L. Troutman, and T. W. Mathias from the on-site Raytheon Testing Laboratory conducted the trial mix sample preparation and testing in the laboratory and calibrated the G. L. Throop equipment for the field test. They also collected and tested samples collected during the field test.

BSRI Construction provided support in operating the pump and preparing the 48 foot long form for the final testing.

Bill Smith and the L. Throop personnel mixed the CLSM for the field tests.

W. Macdonald and A. Albrecht from Celcore, Inc provided technical support for preparing and delivering the pre-formed foam to the auger mixer for the cellular CLSM mixes. Celcore Inc. also provided the MAXFLOW admixtures, the laboratory and field foam generators, and the grout pump for the cellular CLSM mixes.

Dr. S. Wood and the SRTC Strategic Research and Development program provided funding for this program. 
WSRC-TR-98-00271

March 30, 1998

Page 15 of 46

Table 1. Reducing CLSM Trial Mix Formulations Tested at the Raytheon On-Site Laboratory. (CTL Reducing Grout Is Shown for Comparison.)

\begin{tabular}{|c|c|c|c|c|c|c|c|c|}
\hline Ingredients 4040 & Reducing & HP, ZB & RG1: & $\frac{1}{4}$ & & & RG5: & Rab \\
\hline Cement, Type I, lbs/cyd & $1353^{*}$ & 150 & 50 & 150 & 75 & 150 & 120 & 75 \\
\hline Slag, Grade $100,1 \mathrm{bs} / \mathrm{cyd}$ & 209 & -- & 210 & 210 & 210 & 210 & 275 & 210 \\
\hline Fly Ash, lbs/cyd & -- & 500 & 300 & 200 & $375 \%$ & 300 & 165 & 325 \\
\hline Sand, lbs/cyd & 1625 & 2300 & 2300 & 2300 & 2300 & 2300 & 2300 & 2300 \\
\hline Water, gals/cyd & 86.4 & 63 & 60 & 60 & 60 & 60 & 60 & 60 \\
\hline Advaflow, fl oz/cyd & - & 90 & 90 & 90 & $90 \%$ & 90 & 90 & 90 \\
\hline Kelco-crete, gm/cyd & -- & 275 & 275 & 275 & 27.5 & 275 & 275 & 275 \\
\hline Silica Fume, lbs/cyd & 90 & -- & - & -- & 104 & -- & -- & - \\
\hline Sodium Thiosulfate, $1 \mathrm{bs} / \mathrm{cyd}$ & 21 & - & - & -- & Ster & - & -- & 2.1 \\
\hline HRWR, fl.oz/cyd & 250 & -- & -- & -- & W & - & -- & - \\
\hline Retarder, fl.oz/cyd & 150 & -- & - & - & 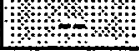 & - & -- & - \\
\hline
\end{tabular}

* Type V Cement

Shading indicates the mix selected for field testing.

Table 2. Cellular (Foamed) CLSM Trial Mix Formulations Tested at the Raytheon On-Site Laboratory.

\begin{tabular}{|c|c|c|c|c|c|c|}
\hline Ingredients: & $\mathrm{RGF} 11$ & RGE2 & RGF3 & RGF4 & MF1 & \%MF2 \\
\hline Cement, Type I, lbs/cyd & 188 & 188 & 188 & 188 & 150 & 15.1500 \\
\hline Fly Ash, Class F, lbs/cyd & 391 & 391 & 391 & 391 & 550 & $1 \% 550 \%$ \\
\hline Sand, lbs/cyd & 1523 & 1523 & 1523 & 1523 & 1275 & 41275 \\
\hline Water, gals/cyd & 458 & 45.8 & 43.0 & 48.0 & 50 & $4.45 \%$ \\
\hline Maxflow Air, lbs/cyd & 24 & 33 & 54 & 54 & 27 & 127 \\
\hline Maxflow RMA, fl oz/cyd & -- & - & -- & - & 82 & 182 \\
\hline Kelco-crete, gms/cyd & -- & & -- & 275 & -- & $1 \%+2$ \\
\hline
\end{tabular}

Shading indicates the mix selected for field testing 
Table 3. A-Area and D-Area Coal Ash Trial Mix Formulations Tested at the Raytheon On-Site Laboratory.

\begin{tabular}{|c|c|c|c|c|c|c|c|}
\hline Ingredients $\quad{ }^{\prime}$ & RGAl' & $\mathrm{RGA2}$ & RGATII & RGAT2 & RGAF 3 & $\mathrm{RGBI}$ & RGD2 \\
\hline $\begin{array}{l}\text { Cement, Type I, } \\
\text { lbs/cyd }\end{array}$ & 165 & 200 & 200 & 200 & $2009 \%$ & 100 & 100 \\
\hline $\begin{array}{l}\text { Slag, Grade 100, } \\
\text { lbs/cyd }\end{array}$ & 210 & -- & -- & -- & $14.4 .4 .4 \%$ & 210 & 210 \\
\hline $\begin{array}{l}\text { Pond Ash, } \\
\text { lbs/cyd }\end{array}$ & $600^{*}$ & $1200^{*}$ & $1200^{*}$ & $1200^{*}$ & $1500 \%$ & $340 * *$ & $1705^{* *}$ \\
\hline $\begin{array}{l}\text { Fly Ash, Class F, } \\
\text { lbs/cyd }\end{array}$ & -- & -- & -- & -- & $44^{400} \%$ & -- & -- \\
\hline $\begin{array}{l}\text { Sand, ASTM C-33, } \\
\text { lbs/cyd }\end{array}$ & 2190 & 1400 & 1400 & 1400 & 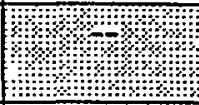 & 2500 & -- \\
\hline $\begin{array}{l}\text { Water, } \\
\text { gals/cyd }\end{array}$ & $\overline{92}$ & 1057 & 105 & 111.5 & $1.4804 \%$ & 67.8 & 115.5 \\
\hline $\begin{array}{l}\text { Maxflow Air, } \\
\text { lbs/cyd }\end{array}$ & -- & -- & 205 & 155 & $1630 \%$ & -- & -- \\
\hline $\begin{array}{l}\text { Maxflow RMA, } \\
\text { fl.oz/cyd }\end{array}$ & -- & -- & -- & -- & 890 & -- & -- \\
\hline $\begin{array}{l}\text { Advaflow, } \\
\text { fl oz/cyd }\end{array}$ & 180 & 180 & -- & -- & $4 \mathbb{1}_{4}$ & 180 & 180 \\
\hline $\begin{array}{l}\text { Kelco-crete, } \\
\text { gms/cyd }\end{array}$ & -- & 275 & -- & -- & भ४ै? & 275 & 275 \\
\hline
\end{tabular}

* A-Area Coal Ash

** D-Area Coal Ash

Shading indicates the mix selected for field testing 
Table 4. Reducing CLSM/Grout Trial Mix Test Results.

\begin{tabular}{|c|c|c|c|c|c|c|c|c|}
\hline 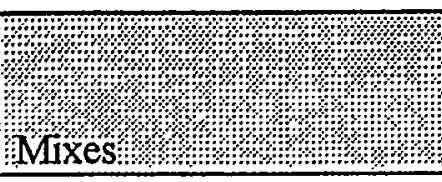 & 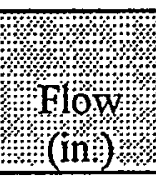 & $\begin{array}{l}\text { Bleed: } \\
\text { Waterts } \\
(\%)\end{array}$ & $\begin{array}{l}\text { Unitit } \\
\text { Wett.t. } \\
(\text { (lbstcft) }\end{array}$ & Content & $\begin{array}{l}4 \\
\text { remp. } \\
(0, \mathrm{r})\end{array}$ & 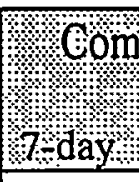 & $\begin{array}{l}\text { tressive } \\
28 .(p s i \\
28 \text { day }\end{array}$ & 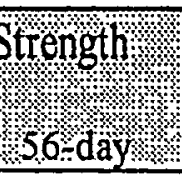 \\
\hline $\begin{array}{l}\text { Reducing Grout } \\
\text { Acceptance Criteria }\end{array}$ & $\begin{array}{r}10 \\
\min \end{array}$ & 0 & $\begin{array}{r}80 \\
\min .\end{array}$ & N/A & $\begin{array}{c}90 \\
\max .\end{array}$ & $\begin{array}{l}50^{\# \#} \\
\min .\end{array}$ & $\begin{array}{l}500 \\
\text { min. }\end{array}$ & $\begin{array}{l}500 \\
\text { min. }\end{array}$ \\
\hline CTL Reducing Grout & $\begin{array}{c}4^{\#} \\
\text { seconds }\end{array}$ & 0 & 128 & 4 & 85 & 6570 & 9725 & $10,700^{*}$ \\
\hline HP-ZB CLSM & 10.50 & 0 & & & & ** & 230 & $710^{*}$ \\
\hline \multicolumn{9}{|l|}{ TEST MIXES } \\
\hline RG1 & 11.13 & 0 & 1204 & 6.6 & 84 & ** & ** & 1230 \\
\hline RG2 & 1200 & 0 & 1205 & 66 & 76 & $* *$ & $* *$ & 1550 \\
\hline 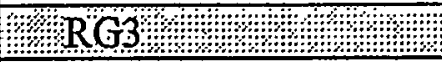 & 1150 & 40 & $120 \%$ & 68.8 & 78 & 3.60 & 1085 & 1300 \\
\hline RG4 & 1175 & 0 & 1222 & 5.5 & 78 & 420 & 1420 & 1620 \\
\hline RG5 & 11.88 & 0 & 1196 & 70 & 78 & 670 & 1465 & 1580 \\
\hline RG6 & 1150 & 0 & 1210 & 57 & 77 & 380 & 1080 & 1320 \\
\hline
\end{tabular}

* 90-day Compressive Strength

** No Cylinders Were Made

\# Flow evaluated by the Japanese specification, Kordan $304{ }^{3}$

\#\# The original acceptance developed by WSRC and CTL was $>500$ psi after 72 hours.

Shading indicates the mix selected for field testing

Table 5. Cellular (Foamed) ZB CLSM Test Results

\begin{tabular}{|c|c|c|c|c|c|c|c|c|}
\hline 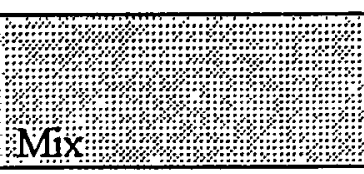 & Flow & $\begin{array}{l}\text { Bleed } \\
\text { Water } \\
\text { Wato } \\
(\%)\end{array}$ & $\begin{array}{l}\text { Unit } \\
\text { wits: } \\
(\text { (bos/cft })\end{array}$ & $\begin{array}{l}\text { Aivita } \\
\text { content } \\
(\%)\end{array}$ & 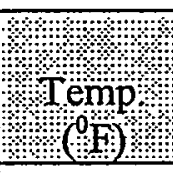 & 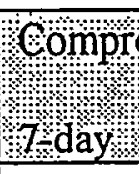 & $\begin{array}{l}\text { sive:sti } \\
\text { spsi } \\
\text { 28:day }\end{array}$ & nogth \\
\hline $\begin{array}{l}\text { Tank Fill CLSM } \\
\text { Acceptance Criteria }\end{array}$ & $\begin{array}{l}10 \\
\min .\end{array}$ & 0 & $\begin{array}{r}80 \\
\min \\
\end{array}$ & N/A & $90 \max$. & $\begin{array}{c}20 \\
\text { min. }\end{array}$ & $\begin{array}{l}50 \\
\min \end{array}$ & $\begin{array}{l}120 \\
\min .\end{array}$ \\
\hline \multicolumn{9}{|l|}{ TEST MIXES } \\
\hline RGF1 & 11.00 & 50 & 90.4 & 18.1 & 66 & 40 & 75 & 140 \\
\hline RGF2 & 1075 & 40 & 863 & 19.8 & 64 & 30 & 55 & 135 \\
\hline RGF3 & 1100 & 30 & 808 & 21.8 & 70 & 60 & 140 & 180 \\
\hline RGF4 & 1075 & 60 & 8517 & 16.6 & 72 & 90 & 203 & 240 \\
\hline MF1 & 1450 & 3.0 & 8457 & 278 & 66 & 27 & 45 & 132 \\
\hline MF2 & 1200 & $0=0$ & $849: 9$ & 10288 & $1.65 \%$ & 35 & 75 & 167 \\
\hline
\end{tabular}

Shading indicates the mix selected for field testing 
WSRC-TR-98-00271

March 30, 1998

Page 18 of 46

Table 6. A-Area and D-Area Coal Ash HP-ZB Trial Mix Test Results.

\begin{tabular}{|c|c|c|c|c|c|c|c|c|}
\hline 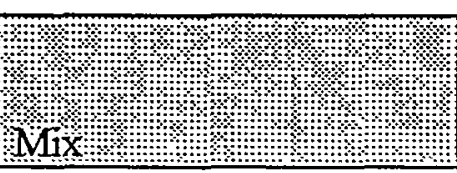 & (Flow: & $\begin{array}{l}\text { Bileed: } \\
\text { Water } \\
(\%) \\
(\%)\end{array}$ & $\begin{array}{l}\text { Unit? } \\
\text { Wh:t: } \\
(\text { lbs/cft })\end{array}$ & $\begin{array}{l}\text { Airt } \\
\text { (ontent } \\
(\%)\end{array}$ & 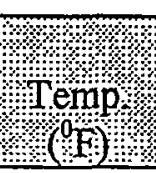 & Comp & $\begin{array}{l}\text { Ssyesit } \\
\text { (psi) } \\
28 \text { day }\end{array}$ & ength? \\
\hline $\begin{array}{l}\text { Tank Fill CLSM } \\
\text { Acceptance Criteria }\end{array}$ & $10 \mathrm{~min}$. & 0 & $80 \mathrm{~min}$ & N/A & $90 \max$. & $\begin{array}{c}20 \\
\min .\end{array}$ & $\begin{array}{l}50 \\
\text { min. }\end{array}$ & $\begin{array}{l}120 \\
\text { min. }\end{array}$ \\
\hline \multicolumn{9}{|l|}{ TEST MIXES } \\
\hline RGAl & 110 & 80 & 109.8 & 74 & 72 & 65 & 560 & 810 \\
\hline RGA2 & 120 & 10.5 & 103.4 & 85 & 73 & 50 & 125 & * \\
\hline RGAF1 & 975 & 103 & 71.74 & 2038 & 71 & * & * & * \\
\hline RGAF2 & 95 & 120 & 7094 & 21.0 & 69 & * & * & * \\
\hline RGAF3 1016 & 140 & 100 & $8846 \%$ & 275 & 66 & 35 & 45 & 60 \\
\hline RGD1 & 11.5 & $<10$ & 1166 & 86 & 79 & 15 & 165 & 740 \\
\hline RGD2 & 115 & 0 & 100.6 & 11 & 85 & 110 & 425 & 970 \\
\hline
\end{tabular}

* Samples were broken or damaged during stripping and subsequently discarded without testing. Shading indicates the mix selected for field testing 
Table 7. Mix Designs Field Tested at the G. L. Throop, Inc. Auger Batch Plant.

\begin{tabular}{|c|c|c|c|}
\hline $\begin{array}{l}\text { Ingredents } \\
4 \\
\% \\
\%\end{array}$ & Reducing $18 \mathrm{RP} / \mathrm{ZB}$ & 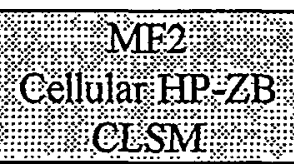 & 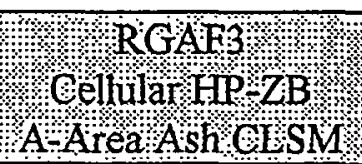 \\
\hline Cement, Type I, lbs/cyd & 75 & 150 & 200 \\
\hline Slag, Grade 100 , lbs/cyd & 210 & - & - \\
\hline Fly Ash, lbs/cyd & 375 & 550 & 400 \\
\hline Sand; lbs/cyd & 2300 & 1275 & -- \\
\hline A-area Coal-Ash, lbs/cyd & -- & -- & 1500 \\
\hline Water, gals/cyd & 60 & 45 & 80 \\
\hline Advaflow, fl oz/cyd & 90 & -- & -- \\
\hline Kelco-crete, gm/cyd & 275 & - & \\
\hline Maxflow Air, lbs/cyd & -- & 27 & 30 \\
\hline Maxflow RMA, fl oz/cyd & -- & $\overline{82}$ & 90 \\
\hline
\end{tabular}

Table 8. Field Test Results for Reducing Grout/CLSM and Two Alternative HLW Tank Fill CLSM Mixes, HP-ZB Cellular CLSM and A-Area Coal Ash HP-ZB CLSM.

\begin{tabular}{|c|c|c|c|c|c|c|c|c|c|c|c|c|}
\hline 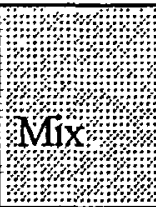 & \multicolumn{2}{|c|}{4.8 Foow } & \multicolumn{2}{|c|}{ 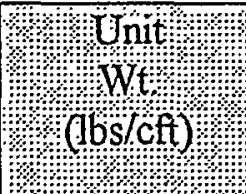 } & \multicolumn{2}{|c|}{ Ain content } & \multicolumn{2}{|c|}{ Temp } & 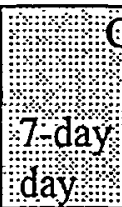 & 4 day & Stren & $20=$ \\
\hline RG3 & & & & 00 & & & & 0 & 330 & 395 & 1095 & 1985 \\
\hline MF2 & $135^{*}$ & $13.5^{\hbar}$ & $985^{\circ}$ & $75^{\#}$ & $185^{*}$ & $198^{\#}$ & $61^{*}$ & $61 \#$ & 80 & 100 & 135 & 420 \\
\hline GAF3 & $14.0^{*}$ & $140^{\sharp}$ & $89.2^{*}$ & $85.1^{\#}$ & $14.5^{*}$ & $18.5^{\#}$ & $58^{*}$ & $58 \#$ & 30 & 35 & 55 & 130 \\
\hline
\end{tabular}

* Samples collected at the augur discharge

\# Samples collected at the pump discharge end

** Samples collected at the truck discharge 
WSRC-TR-98-00271

March 30, 1998

Page 20 of 46

Table 9. Comparison of CTL Reducing Grout and HP-ZB Reducing Grout/CLSM, Mix RG3.

\begin{tabular}{|c|c|c|c|c|c|c|}
\hline 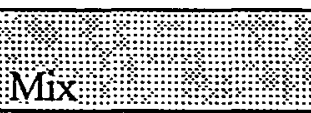 & 4 flow: & 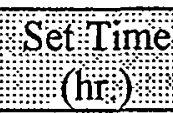 & Temp & $\begin{array}{l}\text { Thiermal } \\
\text {.Cracking }\end{array}$ & $\begin{array}{l}\text { Eift Height } \\
\text { Restriction }\end{array}$ & costpet \\
\hline $\begin{array}{l}\text { CTL Reducing } \\
\text { Grout }\end{array}$ & 4 sec. * & $24-35$ & $350^{\circ} \mathrm{F}$ & Yes & One foot & $\approx \$ 450$ \\
\hline $\begin{array}{l}\text { HP-ZB Reducing } \\
\text { Grout/CLSM } \\
\text { Mix RG3 }\end{array}$ & 11.5 in. ** & $24-30$ & $110^{\circ} \mathrm{F}$ & $\begin{array}{c}\text { Very } \\
\text { Minimal }\end{array}$ & $\begin{array}{c}\text { No lift } \\
\text { Restriction }\end{array}$ & $\approx \$ 80$ \\
\hline
\end{tabular}

* Kordan Flow Cone Method

** ASTM D-6103 Method

* Data from the SRS Tank 17- and 120-F closures are the basis of these estimates

Table 10. Comparison of Tank 17- and 20-F ELSM and Cellular HP-ZB A-Area Coal Ash CLSMand Cellular HP-ZB CLSM.

\begin{tabular}{|c|c|c|c|c|c|}
\hline 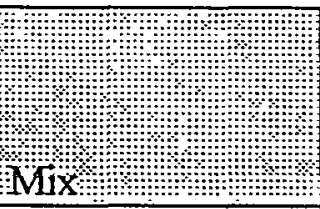 & 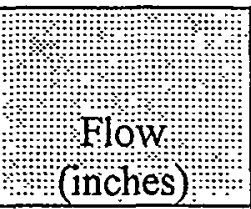 & $\begin{array}{c}\text { Eompressive } \\
\text { Strength } \\
\text { (psi) }\end{array}$ & $\begin{array}{l}\text { Materal } \\
\text { cost w/o } \\
\text { admixtures } \\
\text { per cyd }\end{array}$ & 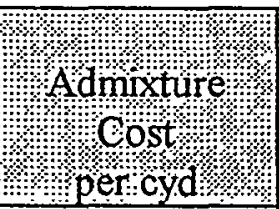 & 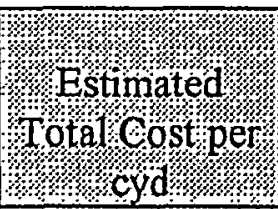 \\
\hline $\begin{array}{l}\text { Tank 17/20 HP- } \\
\text { ZB CLSM }\end{array}$ & 11 & $230 @ 28-d a y$ & $\approx \$ 62^{*}$ & $\$ 18^{*}$ & 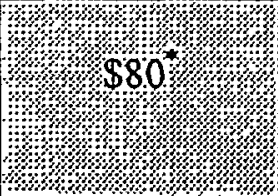 \\
\hline $\begin{array}{l}\text { Cellular HP-ZB } \\
\text { CLSM }\end{array}$ & 135 & $135 @ 28-d a y$ & $\approx \$ 59^{* *}$ & $\approx \$ 10^{* * *}$ & 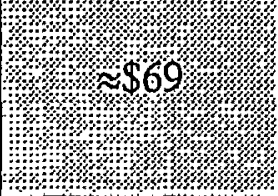 \\
\hline $\begin{array}{l}\text { Cellular A-Area } \\
\text { Coal Ash } \\
\text { HP-ZB CLSM }\end{array}$ & 140 & 5 @28-day & $\approx \$ 55^{\#}$ & $\approx \$ 10^{* * *}$ & 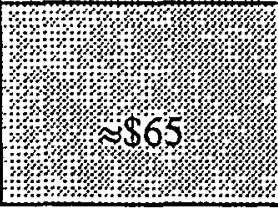 \\
\hline
\end{tabular}

(Cost per cubic yard values are rough estimates for the purpose of relative comparison only.)

* Based on the Tank 17-and 20-F closure costs.

** Based on the tank 17-and 20-F closure costs minus the cost of ASTM C-33 concrete sand replaced by pre-formed foam

*** Based on verbal estimates for admixture costs for MAXFLOW AIR AND RMA obtained form Celcore personnel.

\# Based on the WSRC cost of purchasing A-Area coal ash CLSM from CSR Concrete. This is CLSM for common fill, not HP-ZB CLSM 


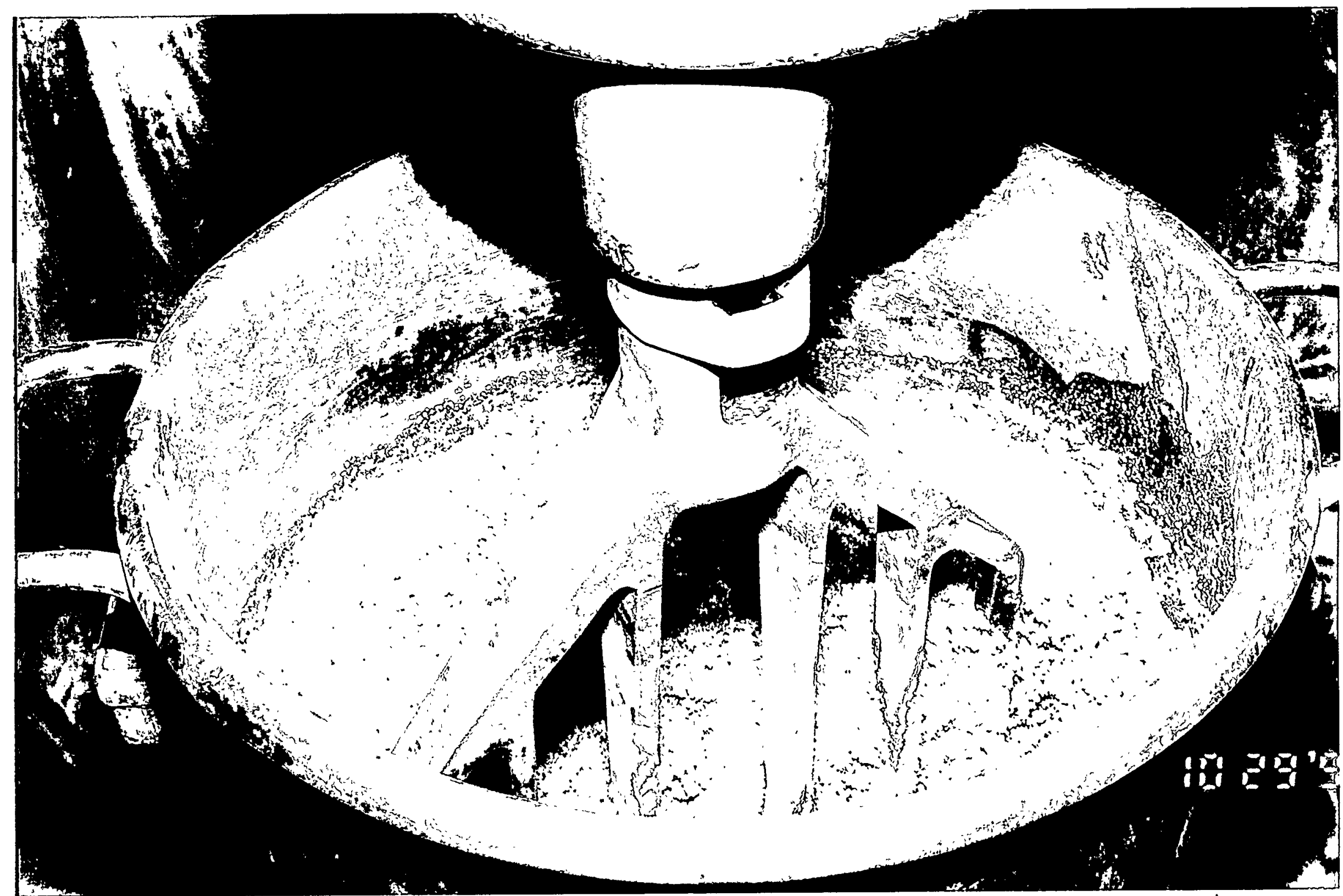

Photograph 1. Reducing HP-ZB CLSM Dry Solids (Sand, Cement, Slag, and Fly Ash) Pre-mixed in a 0.5 Cubic Foot Hobart Mixer. 


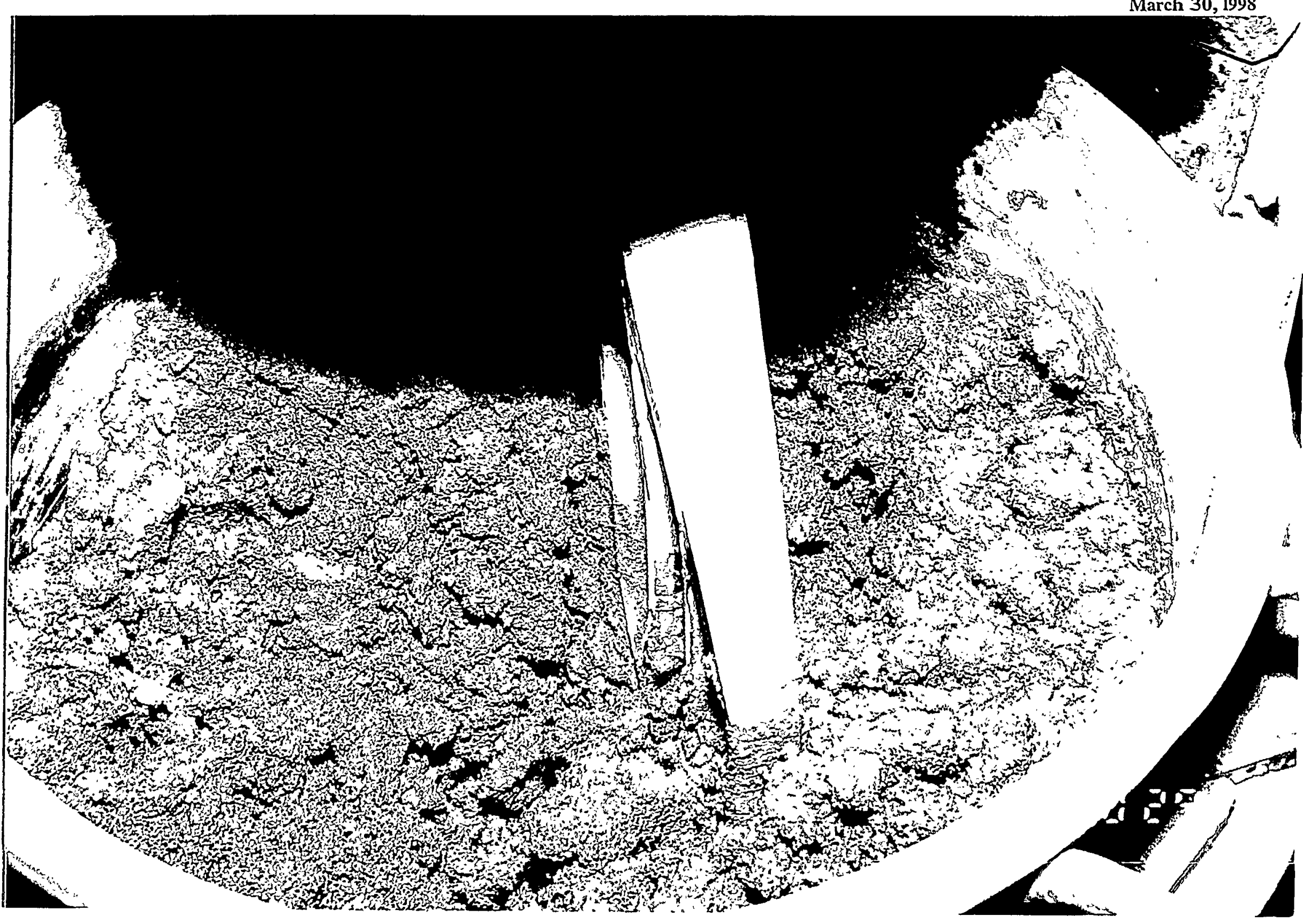

Photograph 2. Consistency of Reducing HP-ZB CLSM (Mix RG3) After the Addition of Water But Before the Addition of the Advaflow and Kelco-Crete. 


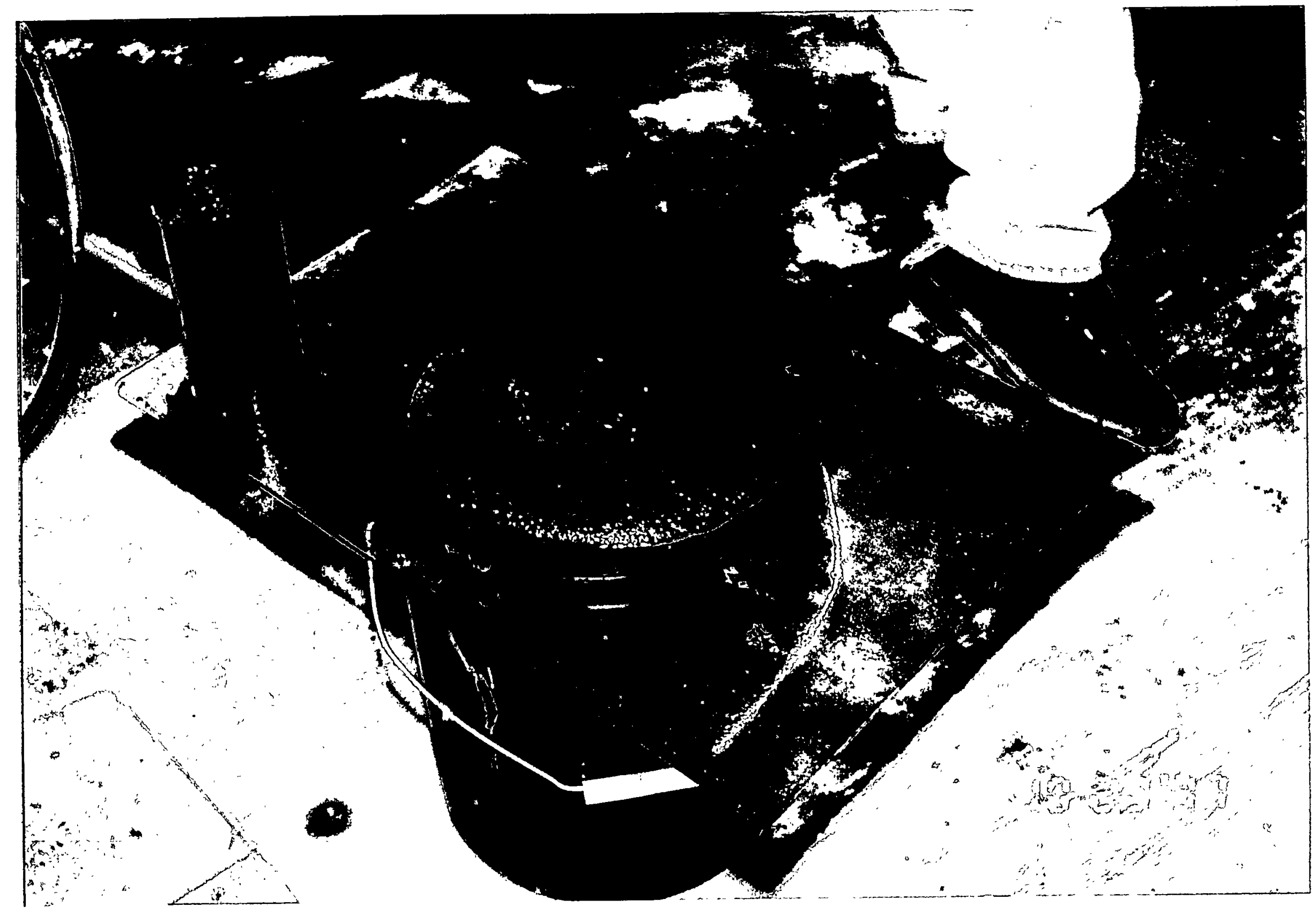

Photograph 3. Consistency and Self-leveling flow of Mix RG3 After Addition of the Advaflow and Kelco-Crete. 


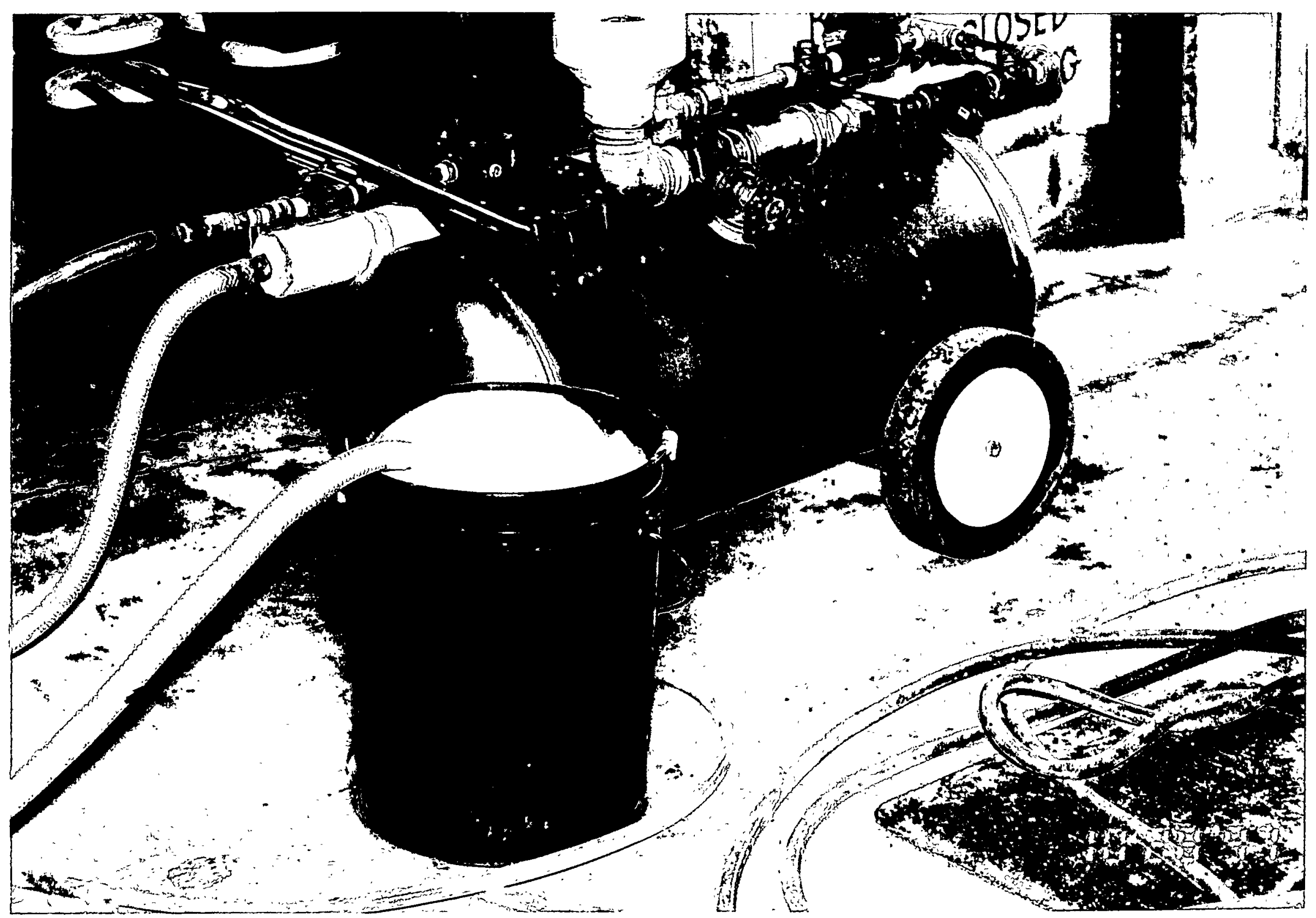

Photograph 4. Small Foam Generator Used to Prepare the MaxFlow Admixture and a Bucket of the Pre-formed Foam Used in Mixes RGF1 to RGF4 and MF1 and MF2. 


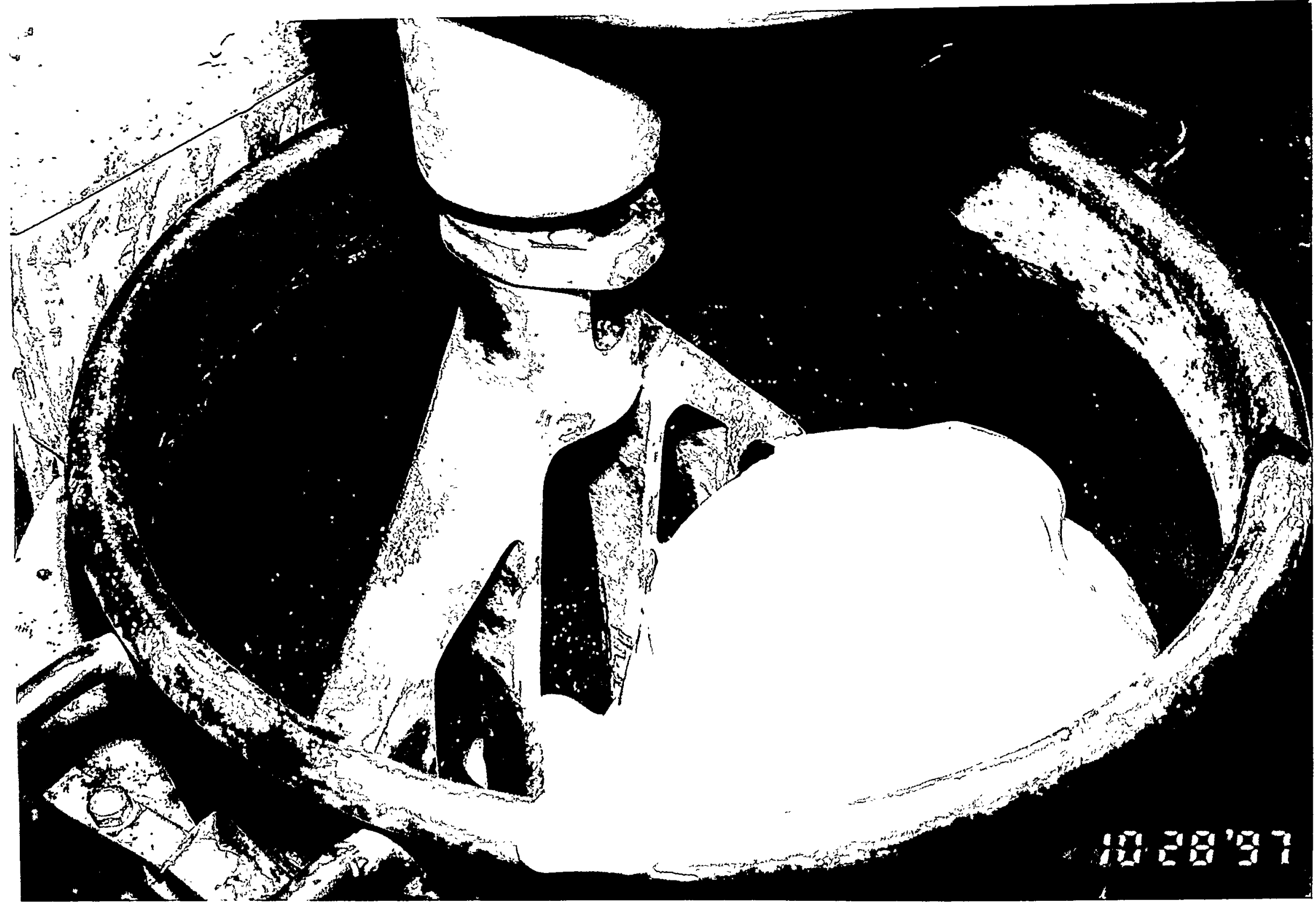

Photograph 5. Pre-formed Foam was Introduced into the CLSM Mixes After All of the Other Ingredients Were Blended. 


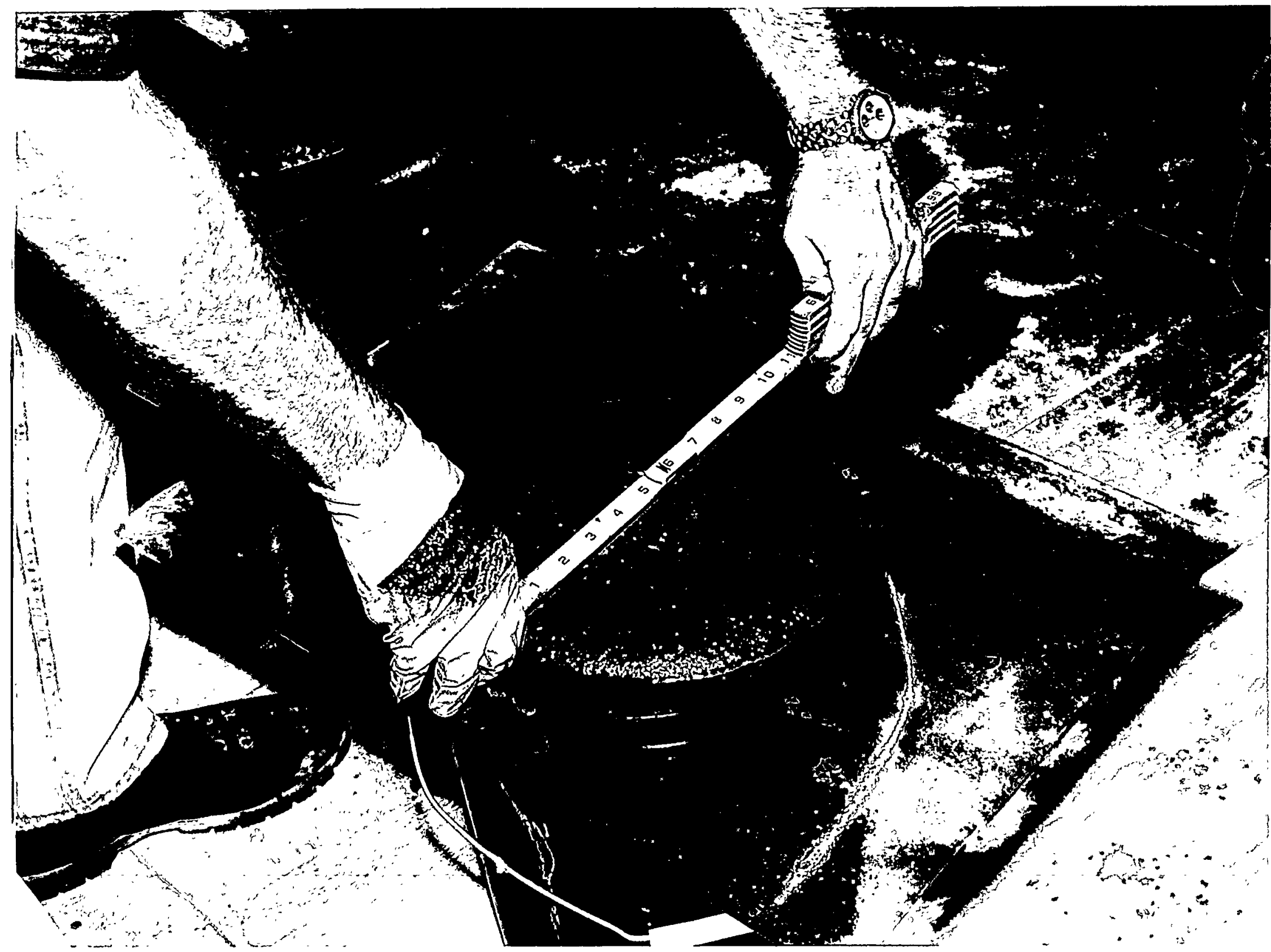

Photograph 6. Consistency and Flow of a Cellular CLSM Mixture Containing Pre-formed Foam but No High Range Water Reducer. 


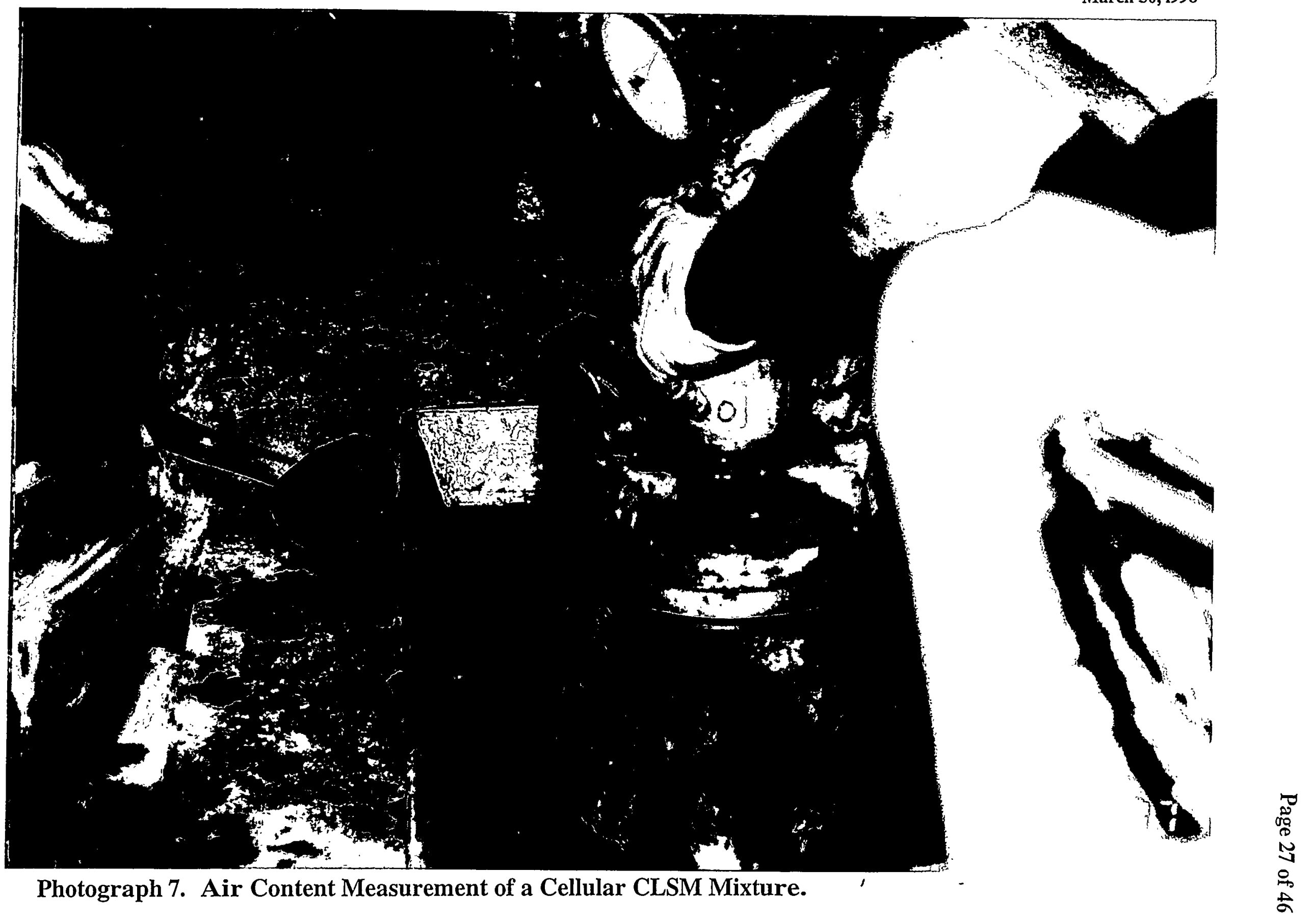




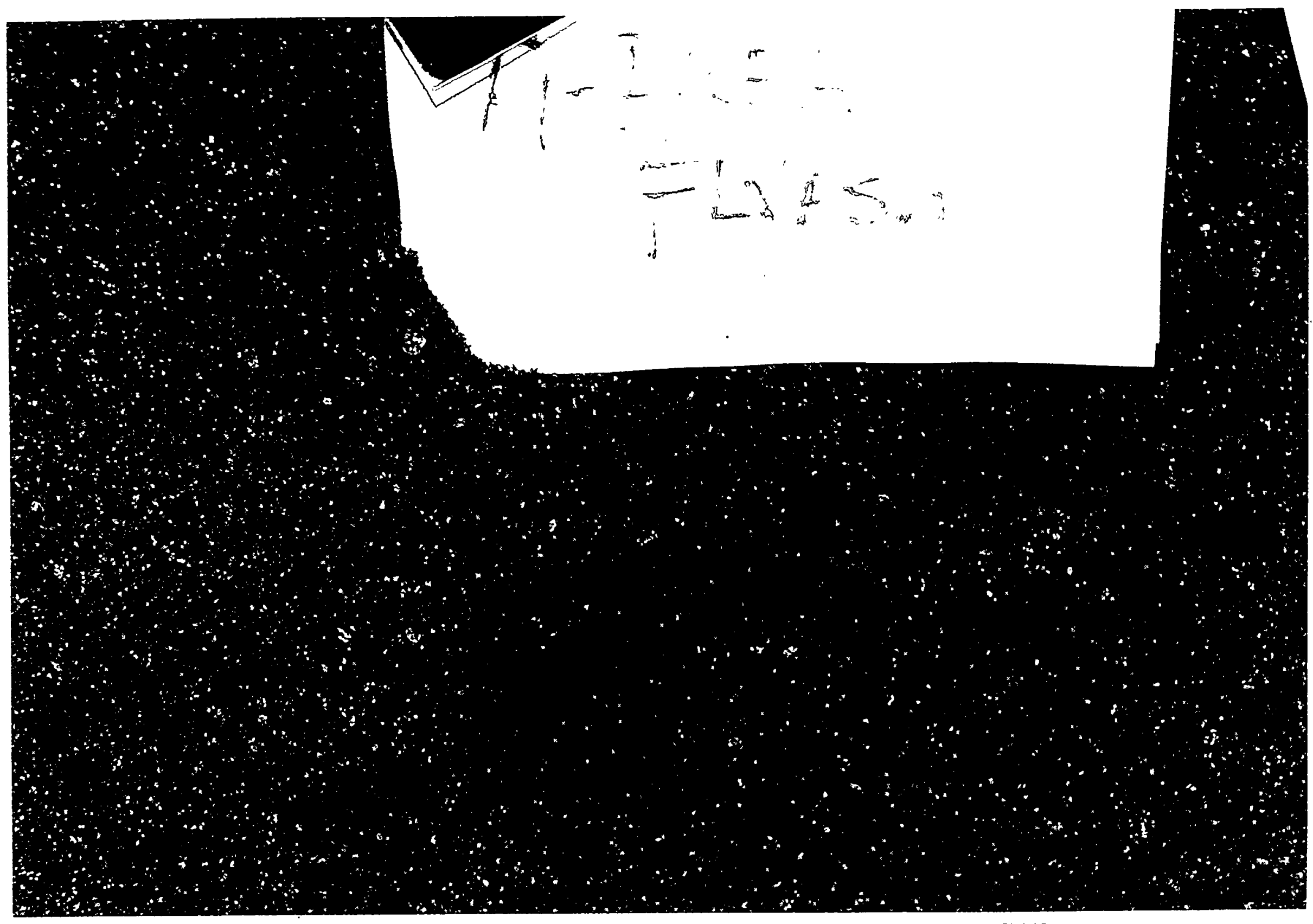

Photograph 8. A-Area Coal Ash Used in CLSM Mixes RGA1, RGA2, RGAF1 to RGAF3. 

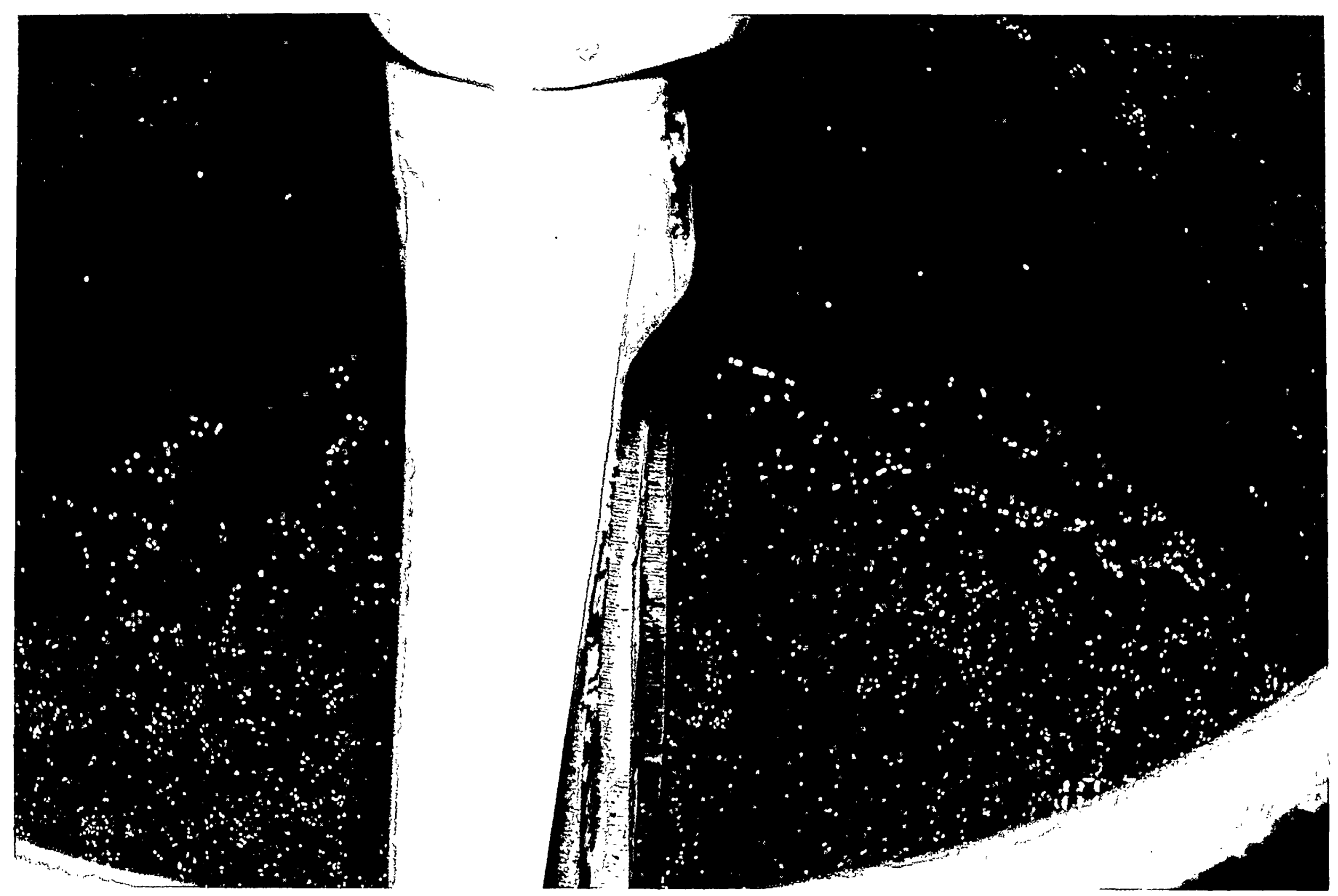

Photograph 9. Consistency of A-Area Coal Ash Cellular CLSM (Mix RGAF3) After the Addition of Water But Before the Addition of the Pre-Formed Foam. 
Page 30 of 46

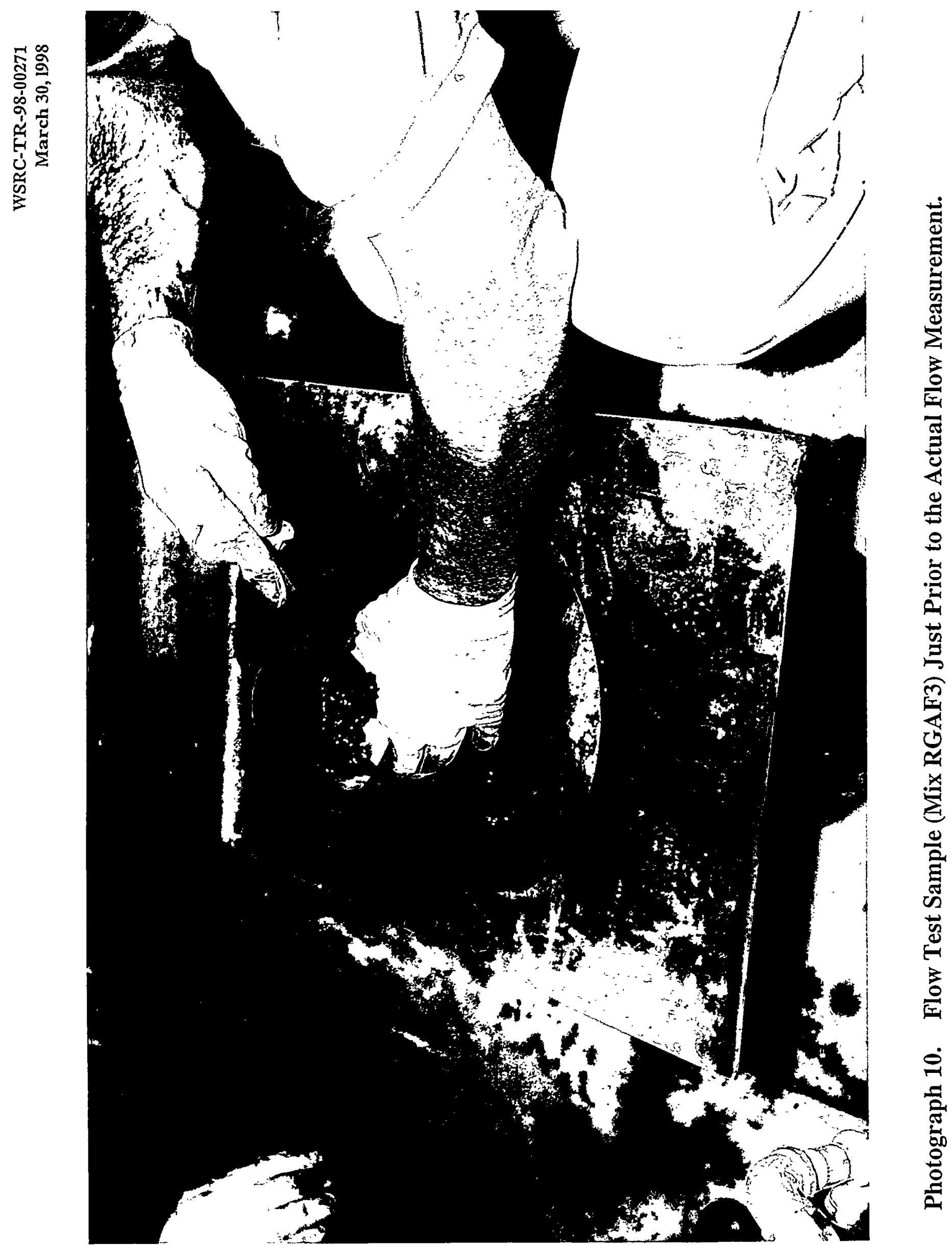




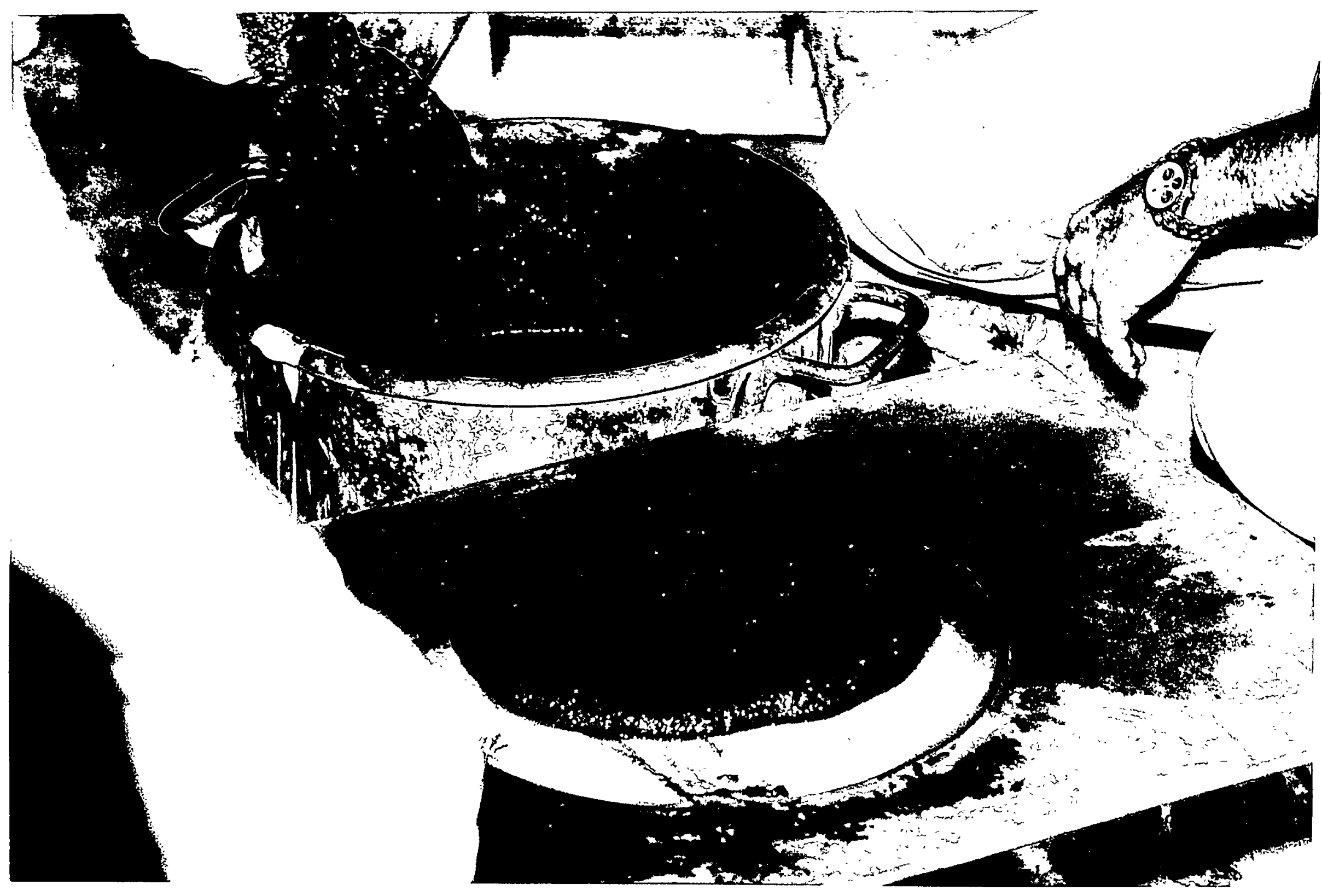

Photograph 11. Consistency and Self Leveling Flow of Mix RGAF3 After the Addition of Pre-Formed Foam and the Maxflow RMA High Range Water Reducer. 


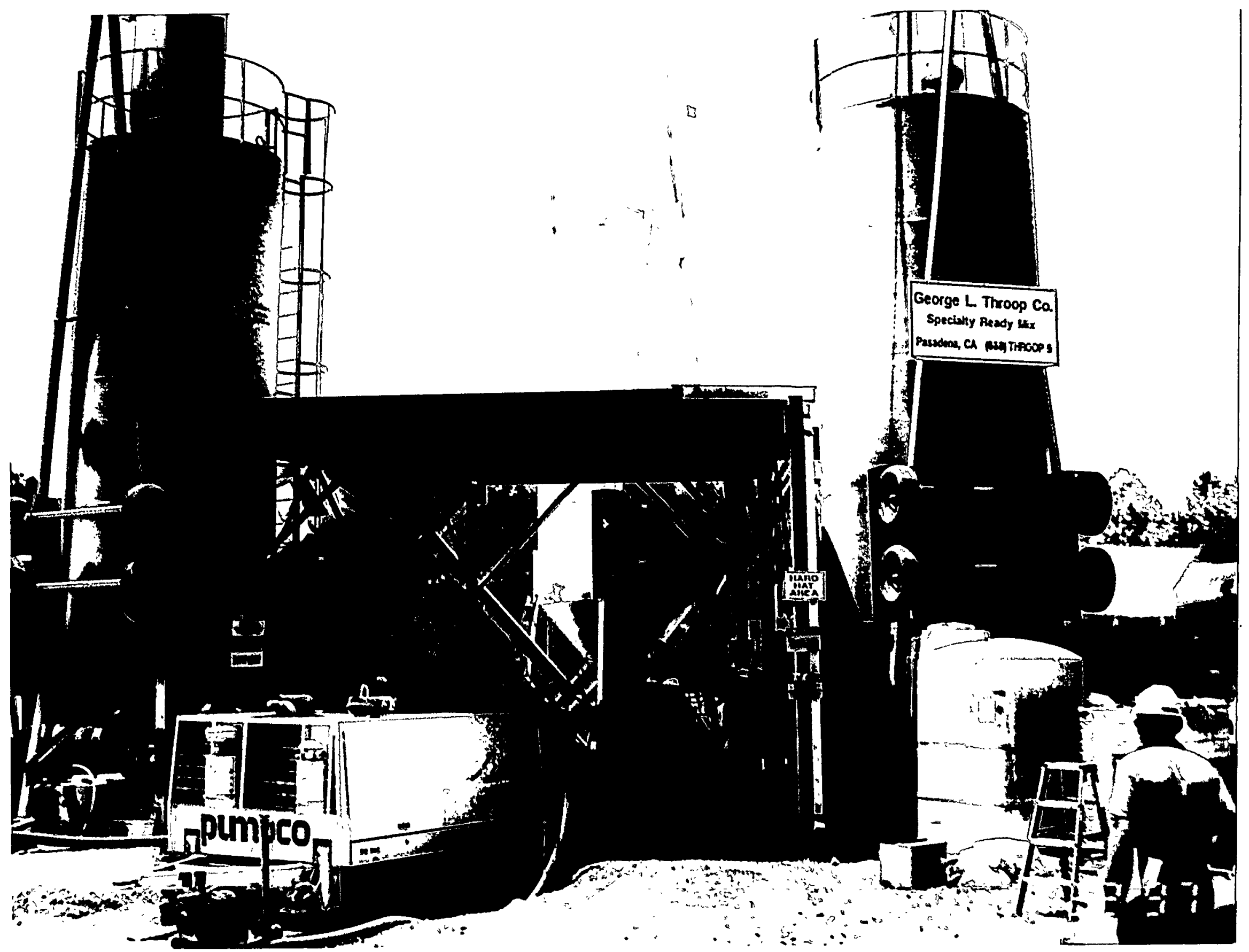

Photograph 12. G. L. Throop, Inc. Continuous Volumetric Auger Plant Located in F-Area Which was Used for the Pilot-Scale Testing. 


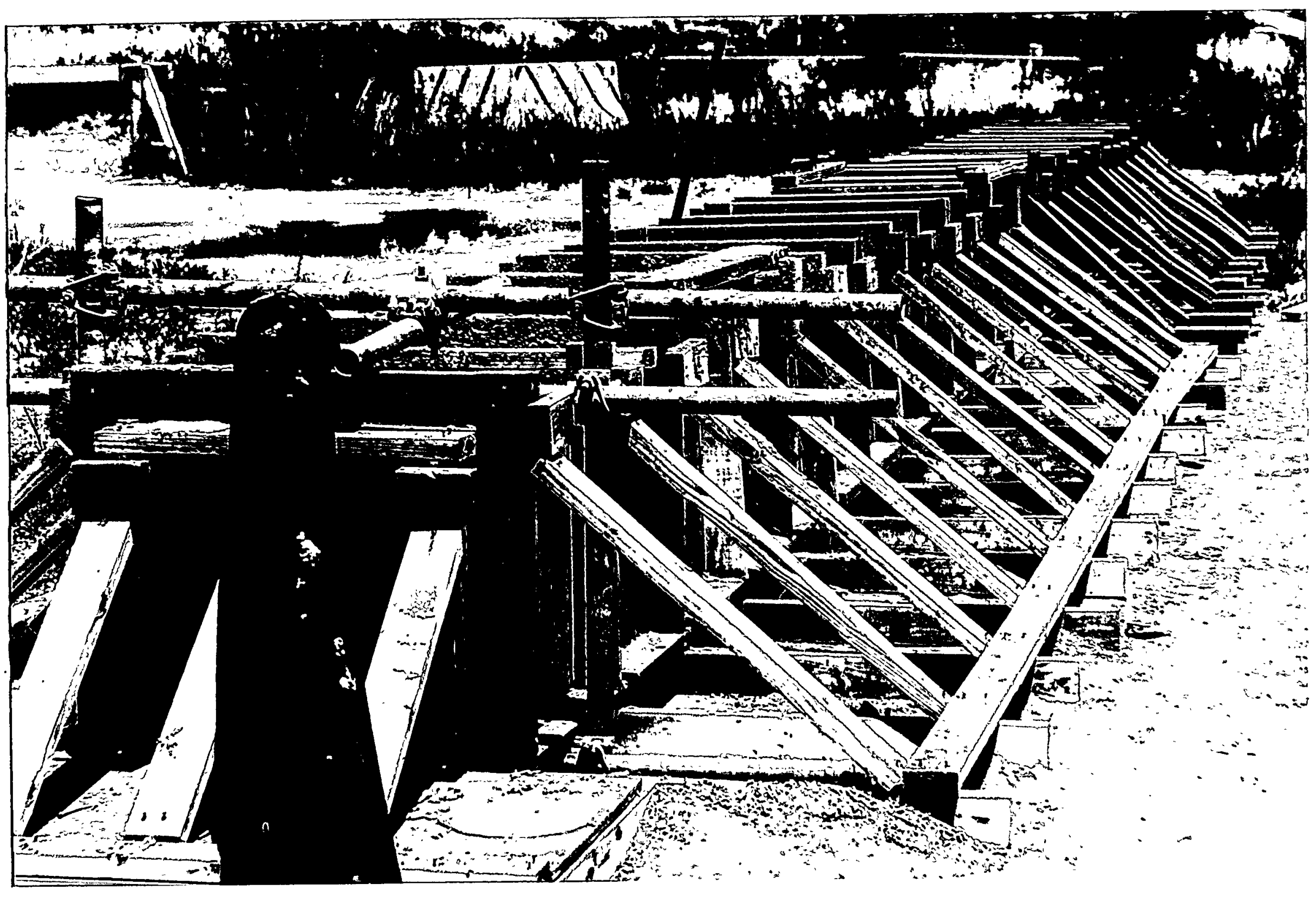

Photograph 13. Test Form (45 x 3 x 3 Feet) and 5 Inch Diameter Transfer Line Used in the Field Testing. 


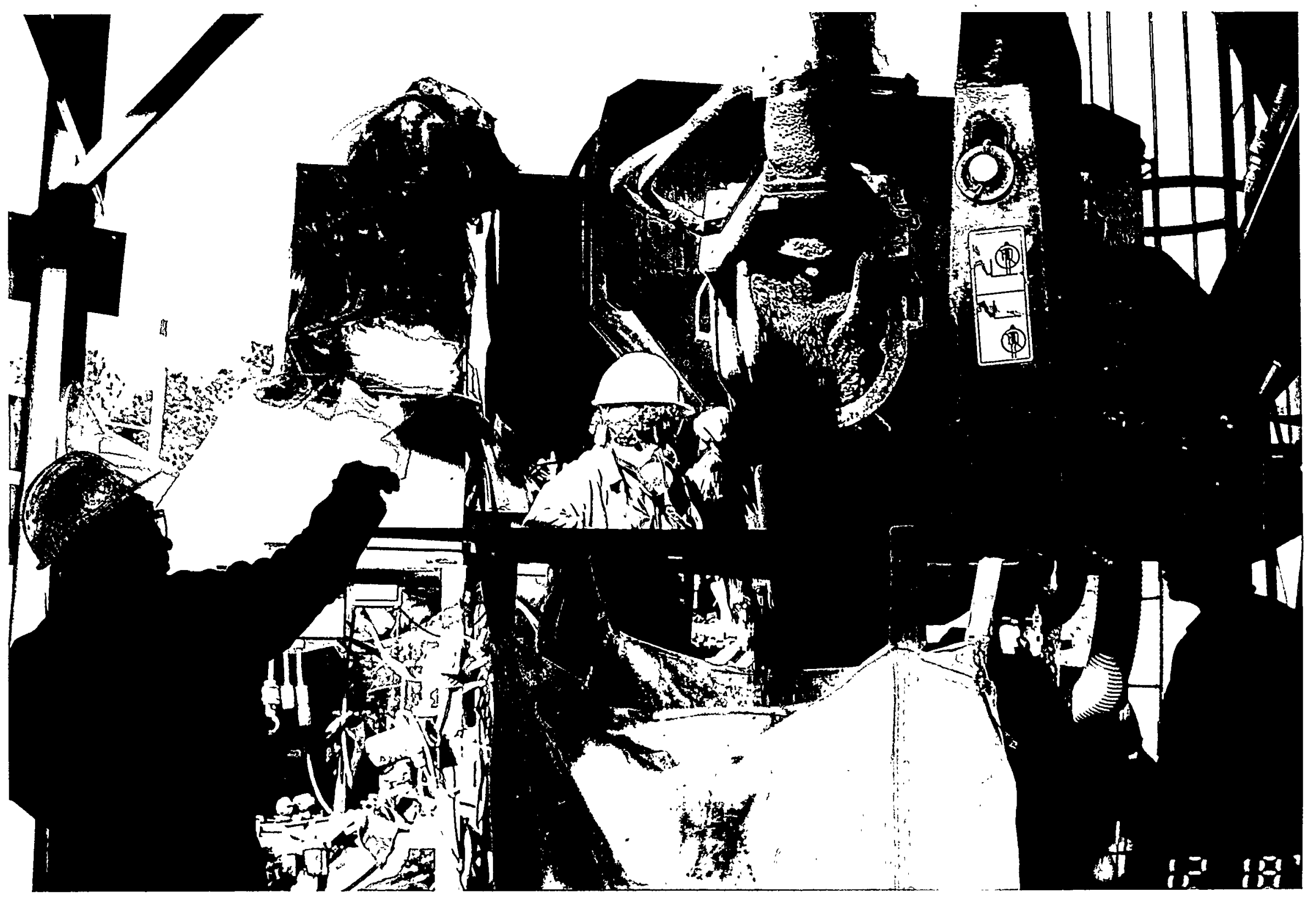

Photograph 14. Five cubic yards of sand, cement and slag were pre weighed for Mix RG3. This material was subsequently transferred to a concrete mixing truck for batching.. 


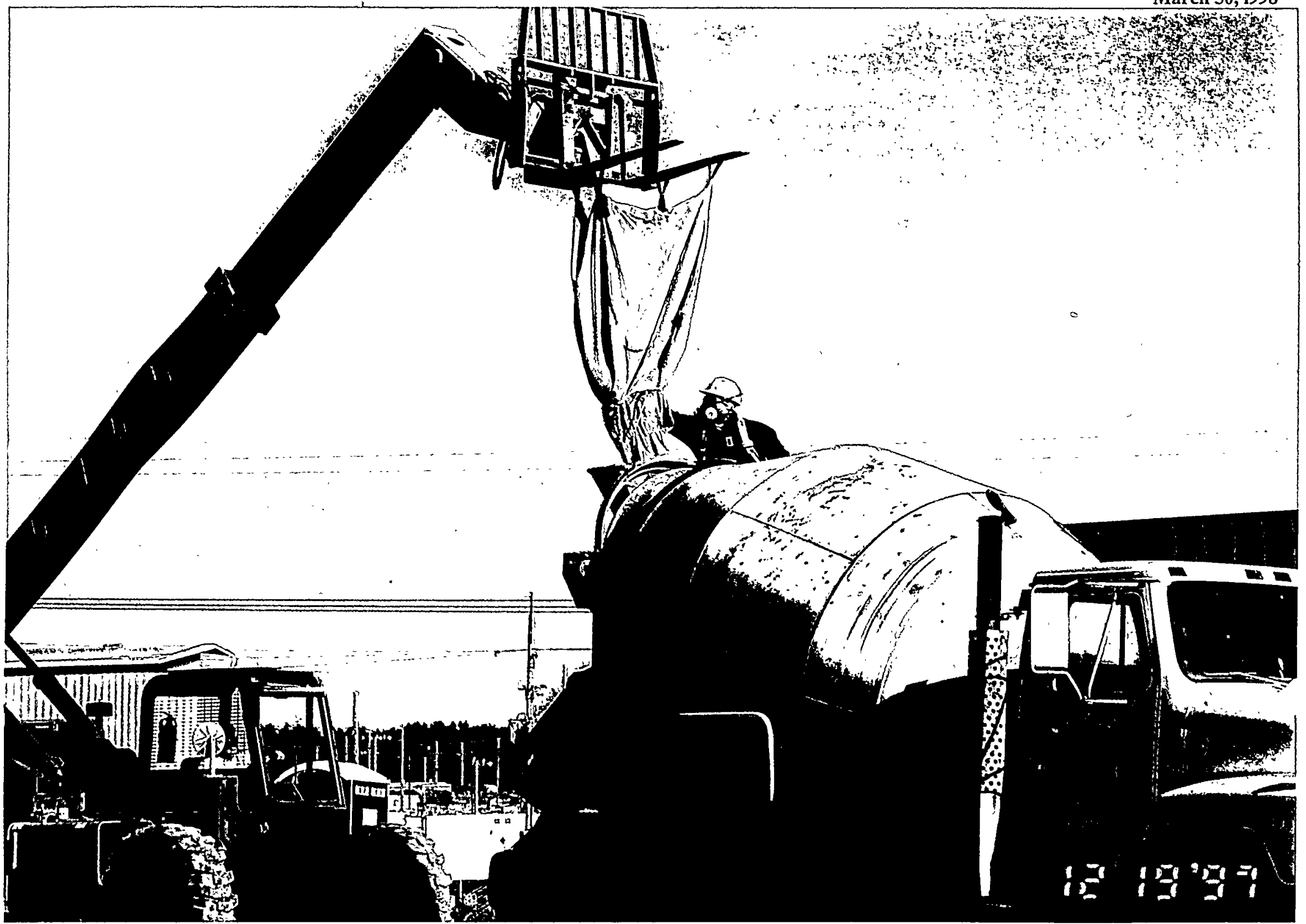

Photograph 15. Dry Solids for Mix RG3 were Weighed at the Troop Plant and Transferred to Super Sacks Which Were Then Emptied into a Concrete Truck for Mixing. After Mixing the CLSM was Discharged to the Grout Pump. 


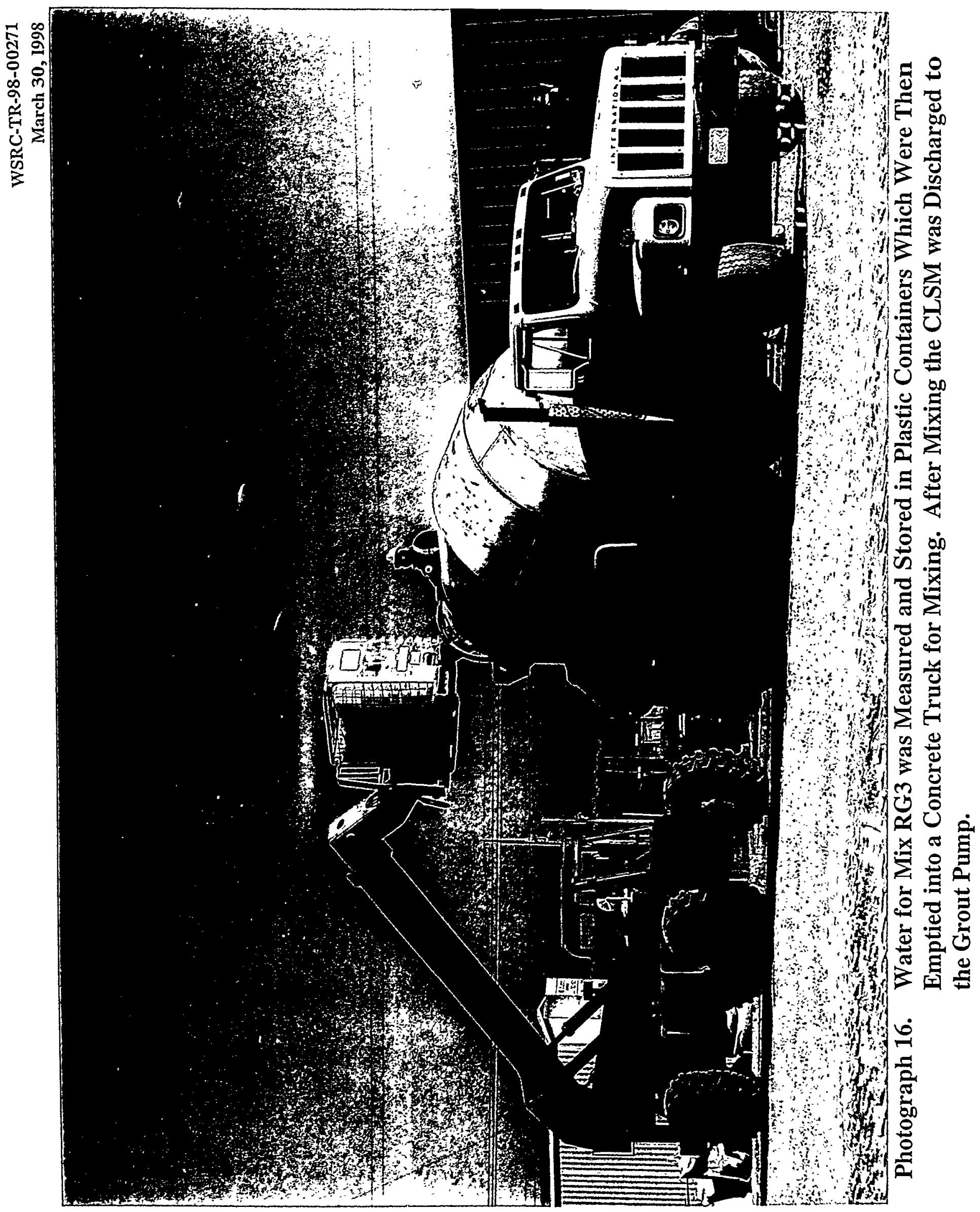


WSRC-TR-98-00271

March 30, 1998

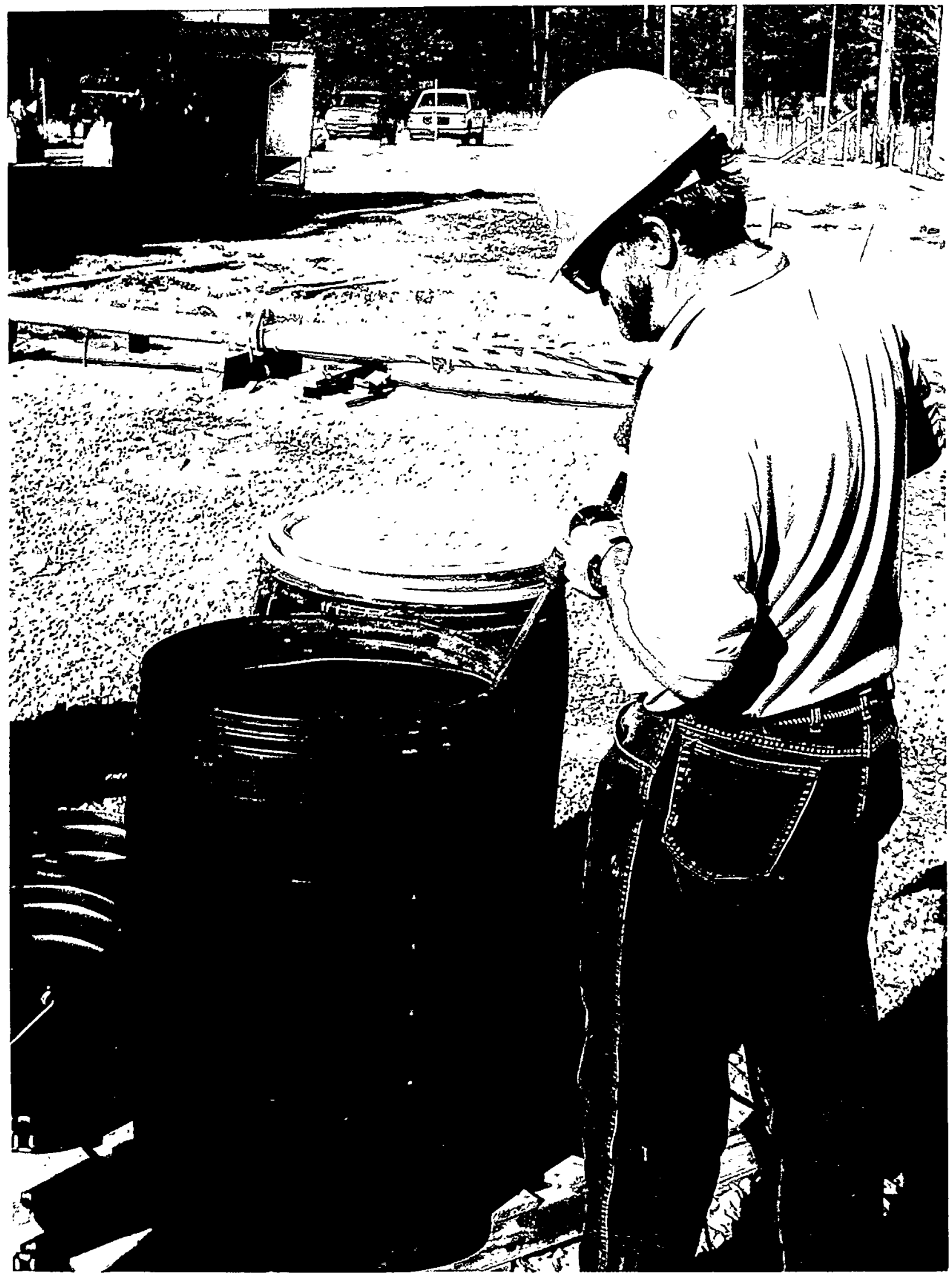

Photograph 17. The MaxFlow Air Admixture was Diluted by W. MacDonald, the Technical Representative from Celcore. 


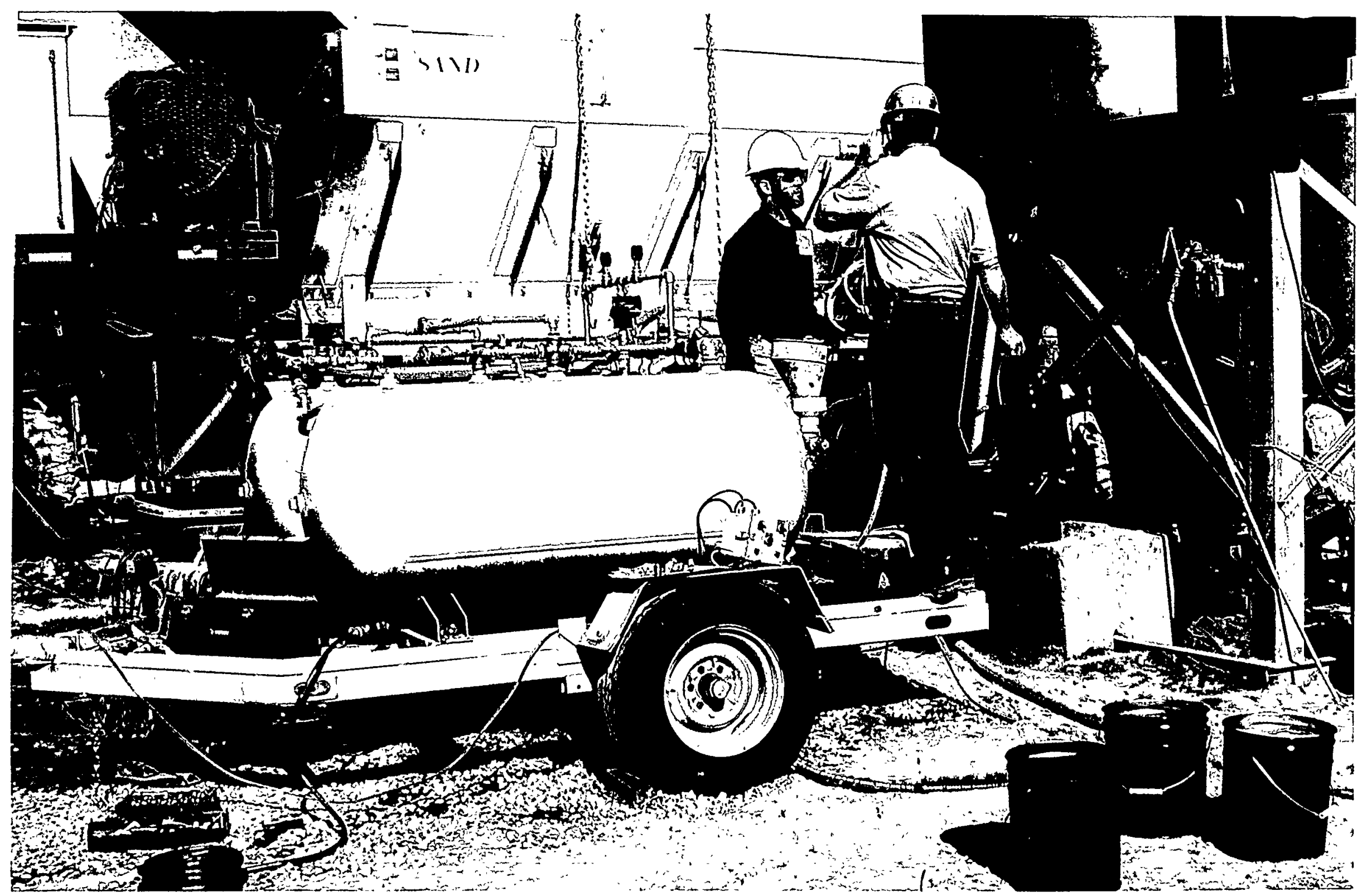

Photograph 18. Foam Generating Equipment Supplied by Celcore, Inc. Which was Used in the Cellular CLSM Field Test. 

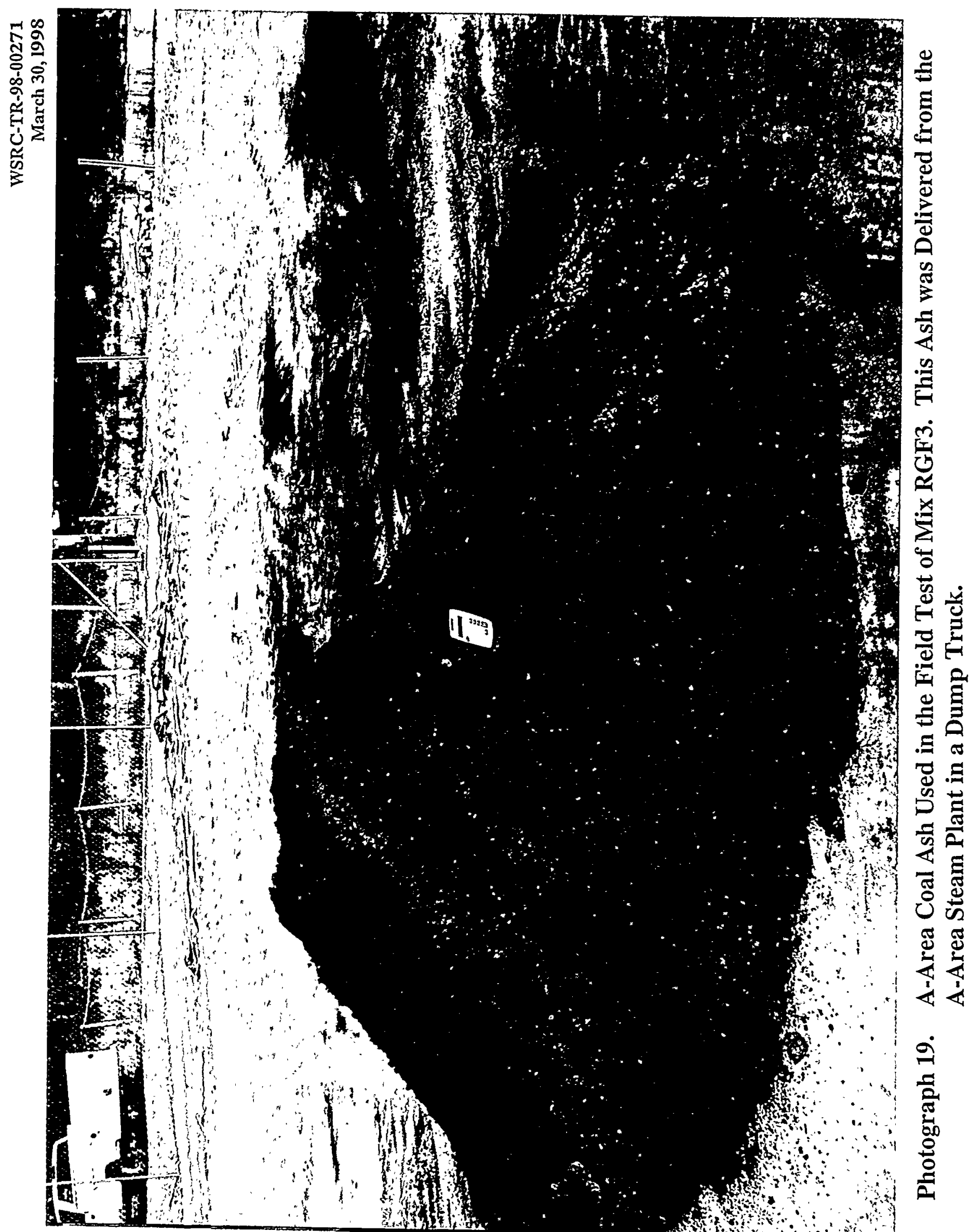


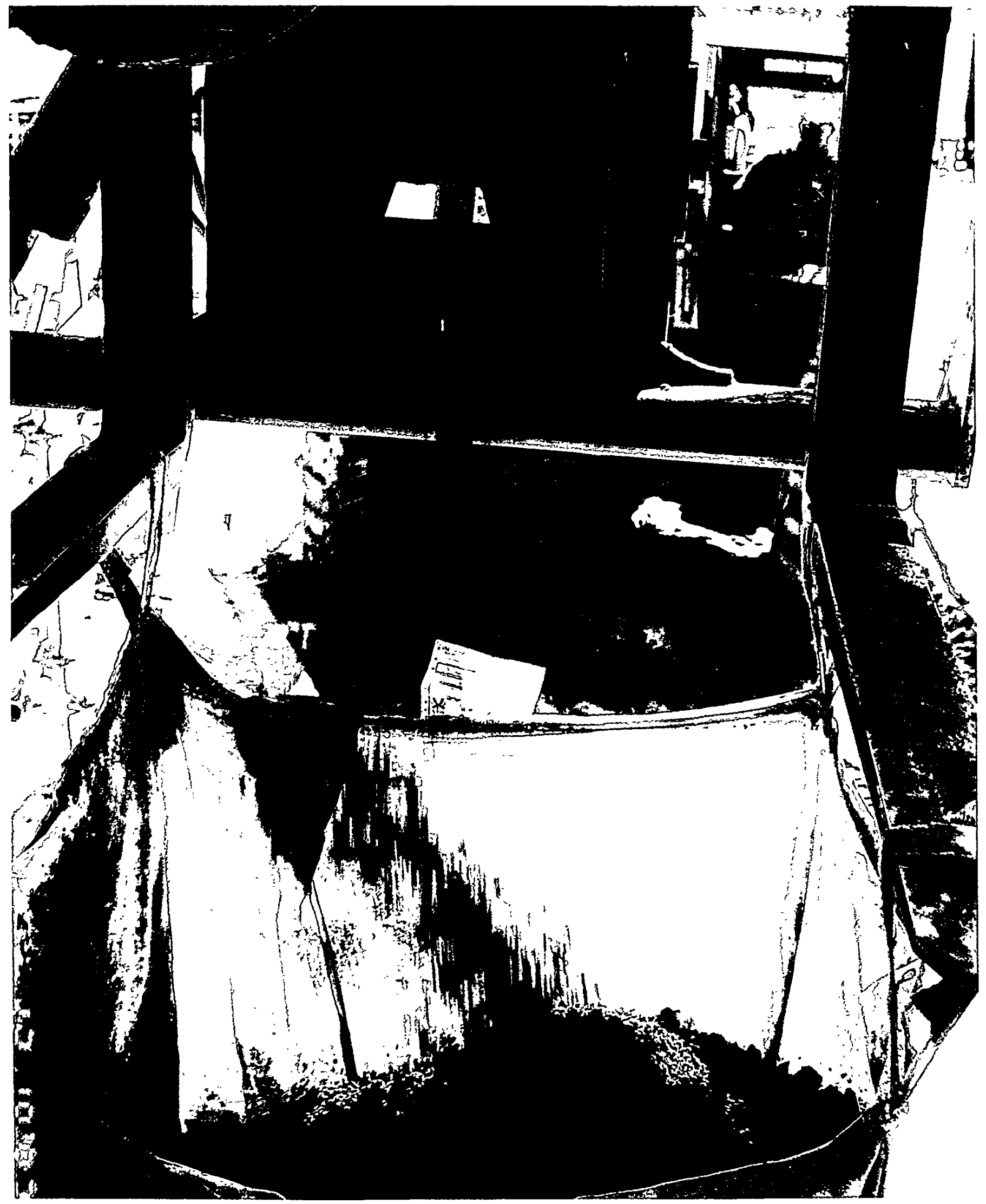

Photograph 20. A-Area Coal Ash was Run Through the Auger Mixer to Crush the Coarse Fraction. No Significant Difference was Observed After Several Passes. 


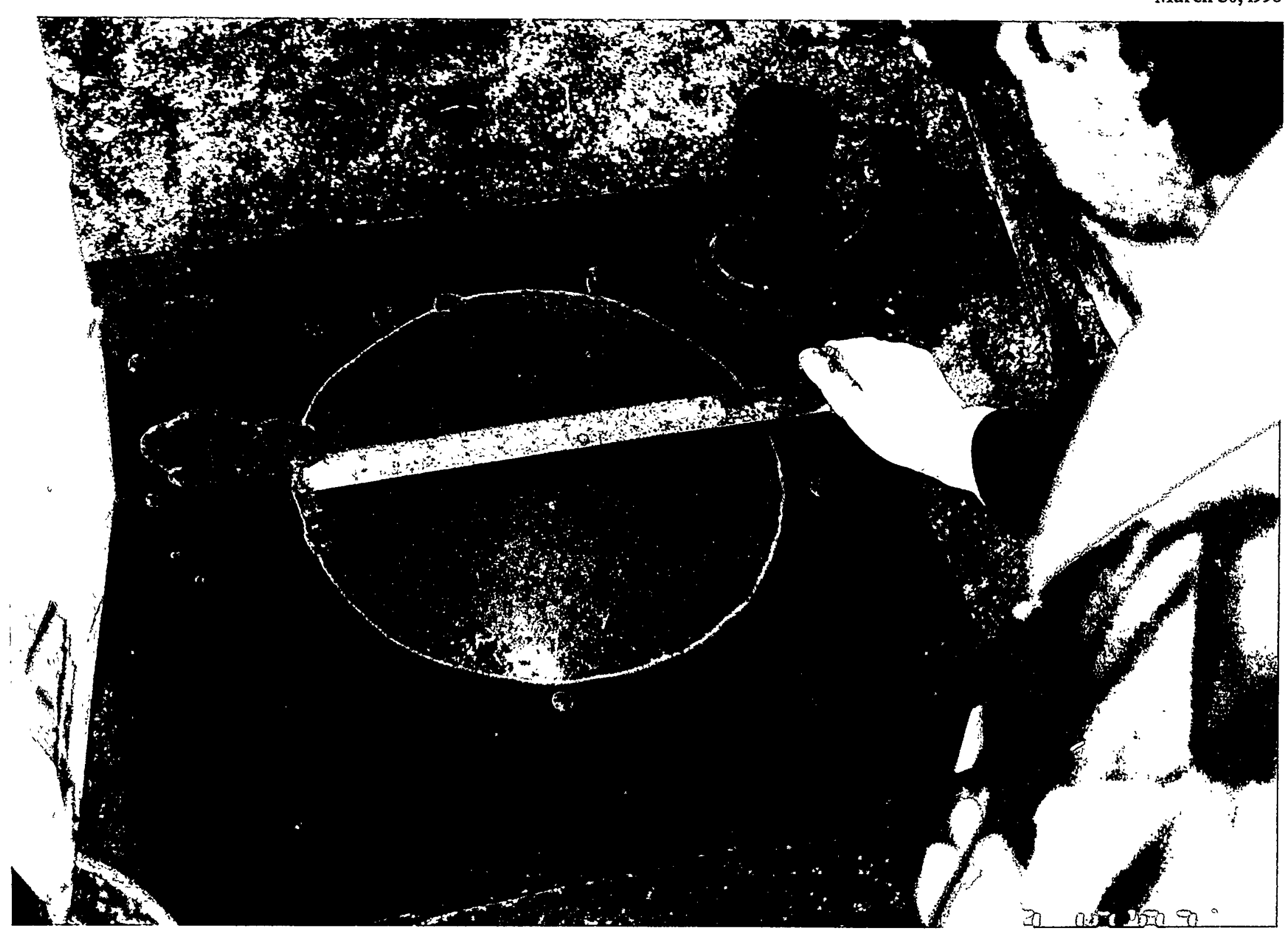

Photograph 22. Consistency and Flow of Mix MF2, Cellular CLSM Collected at the Auger Discharge During the Field Test. 


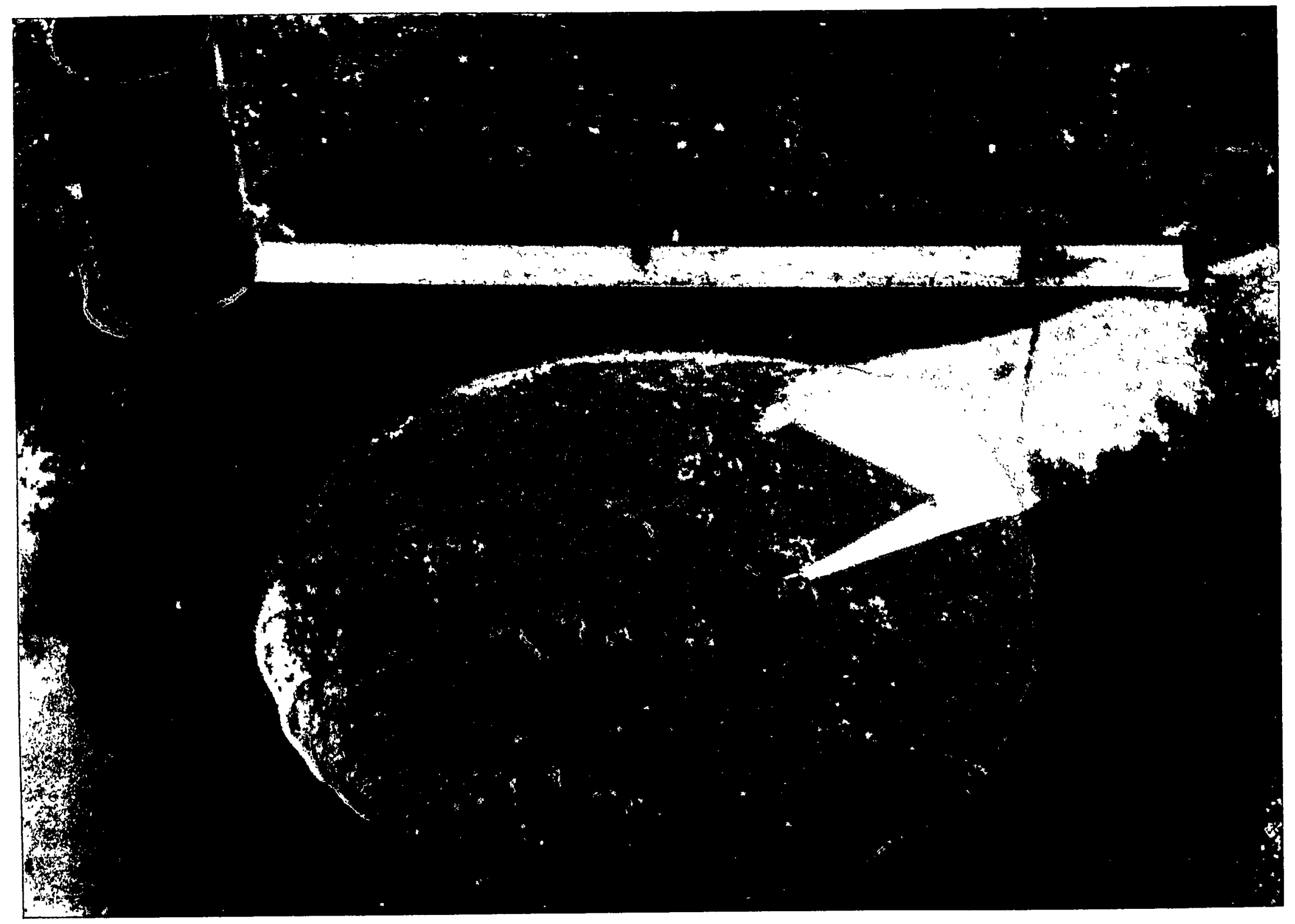

Photograph 23. Consistency and Flow of Mix RGAF3, Cellular A-Area Coal Ash CLSM, Collected at the Auger Discharge During the Field Test. 
WSRC-TR-98-00271 March 30, 1998
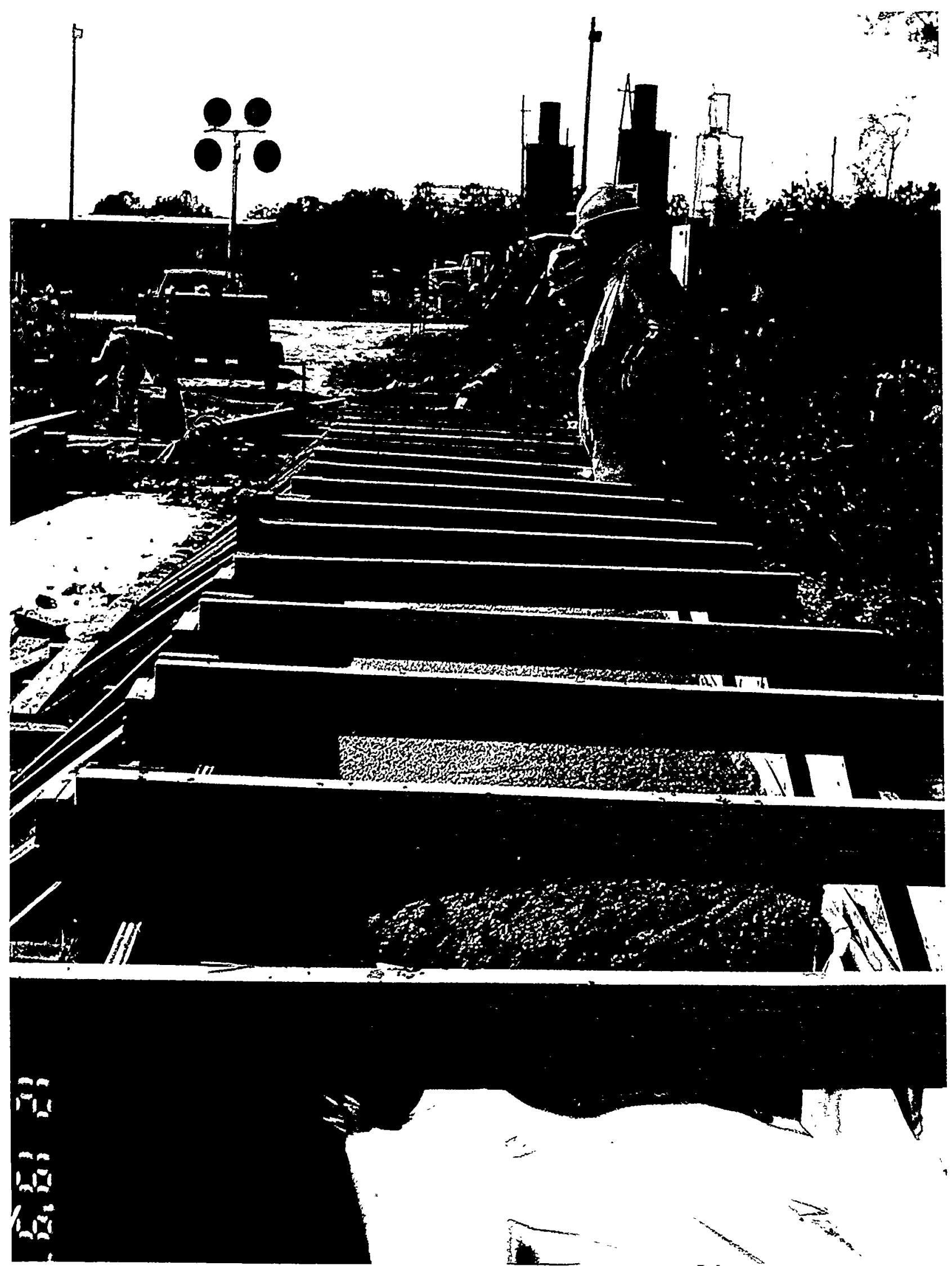

Photograph 24. Flow Characteristics of Reducing CLSM, Mix RG3, in the 45 Foot Long Test Form. 


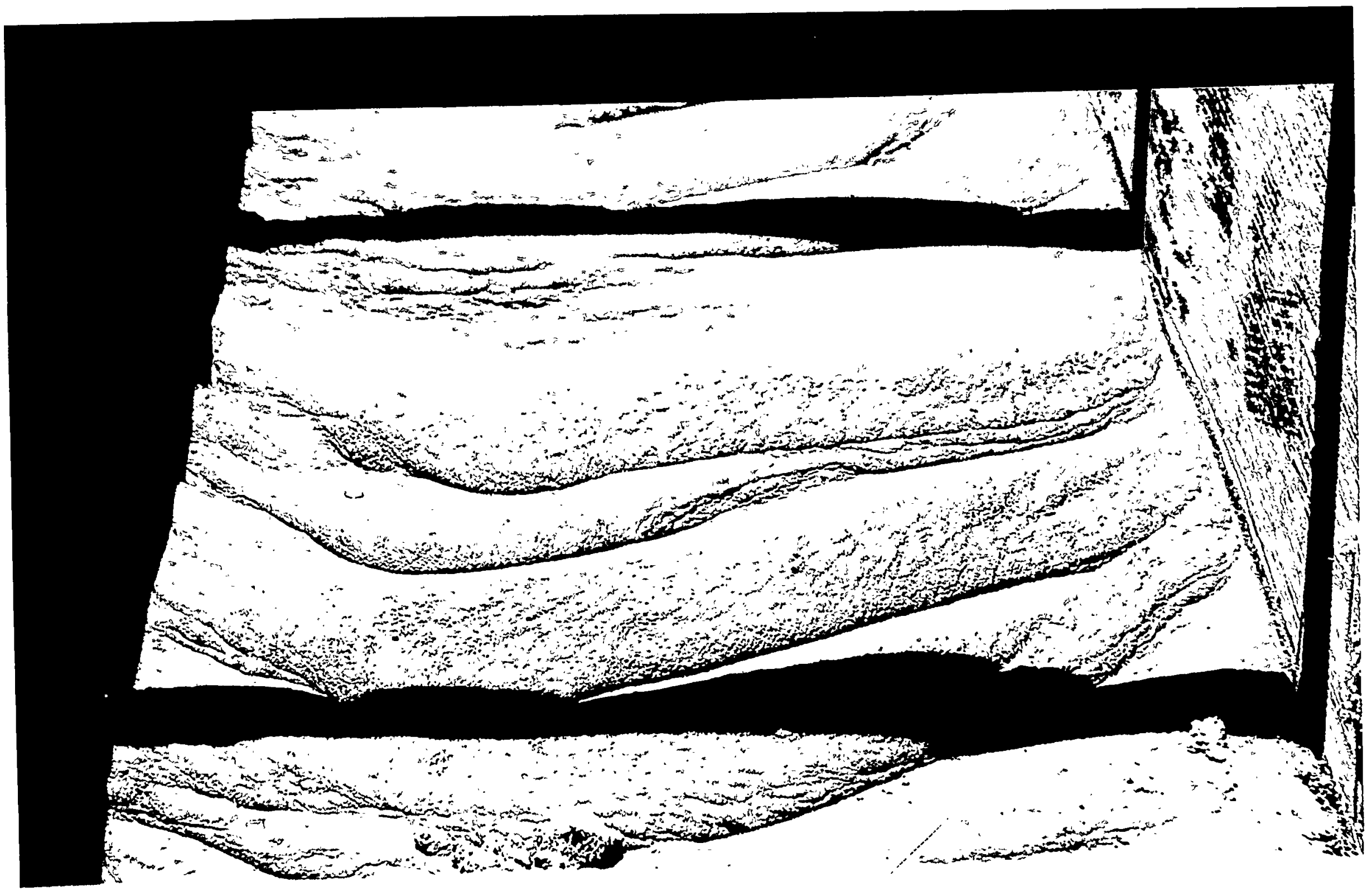

Photograph 25. Flow Characteristics of Cellular CLSM, Mix FM2, in the 45 Foot Long Test Form After Pumping. 


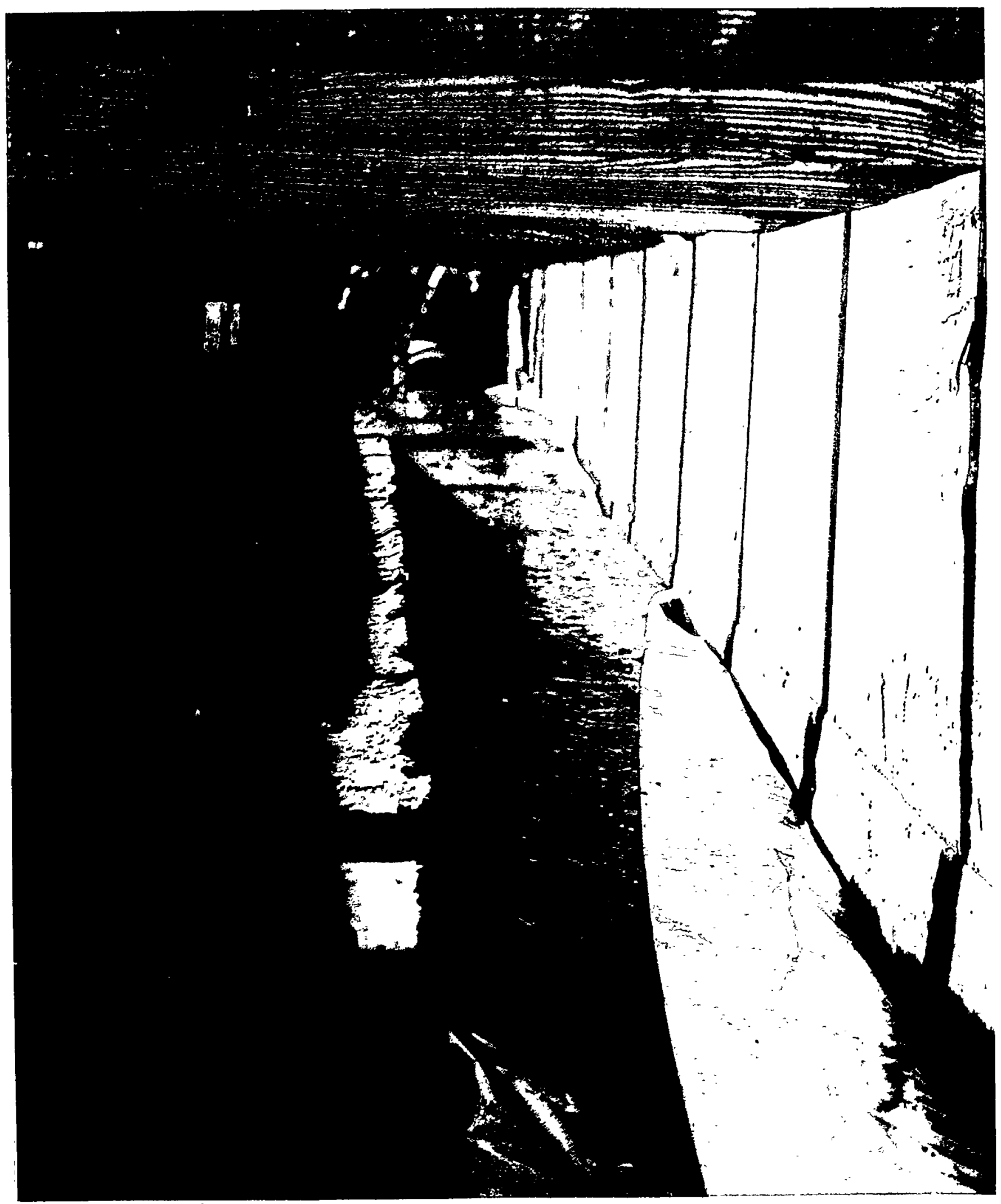

Photograph 26. Flow Characteristics of Cellular A-Area Coal Ash CLSM, RGAF3, in the 45 Foot Long Test Form. 